\title{
1 Plant versus microbial controls on soil aggregate stability in a seasonally dry
}

2 ecosystem

3 Joseph C. Blankinship ${ }^{\mathrm{a}^{*}}$, Steven J. Fonte $^{\mathrm{b}, \mathrm{c}}$, Johan Six $^{\mathrm{d}}$, and Joshua P. Schimel ${ }^{\mathrm{a}}$

$5 \quad{ }^{a}$ Earth Research Institute and Department of Ecology, Evolution, and Marine Biology,

6 University of California at Santa Barbara, Santa Barbara, California, 93106, USA.

7 bepartment of Plant Sciences, University of California at Davis, Davis, California, 95616, 8 USA.

$9{ }^{\mathrm{c}}$ Department of Soil and Crop Sciences, Colorado State University, Fort Collins, Colorado, 10 80523, USA.

11 d Department of Environmental Systems Science, Swiss Federal Institute of Technology, ETH-

12 Zurich, Tannenstrasse 1, 8092 Zurich, Switzerland.

13

$14 *$ Corresponding author

15 E-mail: joseph.blankinship@lifesci.ucsb.edu 


\section{Abstract}

The formation of water-stable macroaggregates in soil is beneficial for many reasons, including carbon (C) sequestration, nutrient retention, and erosion control. A mix of biotic (e.g.,

19 plant $\mathrm{C}$ input, microbial activity) and abiotic factors (e.g., water, mineral interactions) contribute to form macroaggregates. However, in order to better model and manage soil macroaggregates,

21 we need to know more about the relative contributions of these mechanisms. Previous

22 experiments to separate microbial and abiotic mechanisms have been hampered by the need to

23 add sterilant dissolved in water, thus limiting our ability to draw conclusions about the role of

24 soil moisture in controlling aggregation and preventing conclusions about dry soil. Our first goal

25 was to quantify the contribution of plant growth (and fresh plant $\mathrm{C}$ inputs) by continuously

26 removing plants for 2 years in a seasonally dry grassland. Our second goal was to quantify

27 microbial vs. abiotic contributions to macroaggregate formation under a range of soil moisture

28 conditions by using chloroform vapor to sterilize soil without adding water or destroying soil

29 structure. In the field, regardless of dry season length, removing plants reduced the average size

30 of soil aggregates by $22-33 \%$, which was primarily driven by a shift from large

31 macroaggregates ( $2-9 \mathrm{~mm}$ diameter) to small macroaggregates $(0.25-2 \mathrm{~mm})$. In the

32 laboratory, in sterile soils macroaggregate production increased with the moisture content. The

33 resulting physicogenic aggregates appeared planar and angular at both macro- and micro-scales.

34 In contrast, biogenic aggregates were formed most at intermediate moisture levels and were

35 spherical. Our results suggest that - even in dry climates - soil macroaggregates are preserved by

36 the presence of even dead plant roots, but are engineered by live microbes. 
38 Keywords: macroaggregate; soil structure; drought; plant root enmeshment; soil sterilization;

39 chloroform fumigation 


\section{Introduction}

Water-stable aggregates are beneficial in soil for many reasons, including carbon (C)

42 sequestration, nutrient retention, aeration, and erosion control, as well as providing

43 microenvironments for soil biodiversity and an improved seed bed for plants (Tisdall and Oades,

44 1982; Gupta and Germida, 1988; Six et al., 2000; Briar et al., 2011; Kong et al., 2011; Peng et

45 al., 2015). Because water (rain, dry/rewet events, etc.) causes one of the most common

46 disturbances to soil structure, it is desirable to both maintain the water-stability of existing

47 aggregates and promote the formation of larger aggregates. Although microaggregates (53 - 250

$48 \mu \mathrm{m}$ diameter) store $\mathrm{C}$ longest, macroaggregates $(>250 \mu \mathrm{m})$ generally contain more $\mathrm{C}$ (Elliott,

49 1986; Jastrow et al., 1996; Six et al., 2000) because the binding agents are enriched in C;

macroaggregates also act as incubators encouraging the formation of microaggregates (Jastrow,

51 1996). Furthermore, the organic compounds that help bind soil aggregates may themselves be

52 recalcitrant and contribute to long-term C storage (Cheshire, 1977; Foster, 1981; Degens and

53 Sparling, 1995).

Despite the importance of soil aggregates in providing essential ecosystem services, the

mechanisms that control their formation and persistence have not been completely elucidated.

56 This is particularly true for arid and semiarid ecosystems where earthworms and other

57 macroinvertebrates tend to be less abundant (Lavelle et al., 1997), and where seasonal drying

58 make structural resistance to rewetting even more important. Notably lacking is an appreciation

59 of the relative roles of biotic vs. abiotic drivers of aggregate formation. This was pointed out

60 over two decades ago, "methods for assessing soil structure do not usually differentiate between

61 biotic and abiotic factors (Oades, 1993)" and the call for an "explicit incorporation of biology"

62 continues today (Keil and Mayer, 2014). Existing theories suggest that some mix of abiotic (e.g., 
63 water, organic-mineral interactions) and biotic factors (e.g., plant $\mathrm{C}$ input, microbial activity) is

64 needed to form and maintain water-stable macroaggregates (Six and Paustian, 2014). However,

65 in order to better model and manage soil aggregation, we need to identify and better quantify the

66 relative contributions of these mechanisms.

67 The formation of water-stable macroaggregates by abiotic mechanisms (i.e.,

68 "physicogenic aggregates") is generally thought to play a secondary role compared to biology

69 (i.e., "biogenic aggregates"), at least for temperate soils with 2:1 clay minerals. For example, in a

70 recent review on organic-mineral interactions, Keil and Mayer (2014) noted that, "while

71 inorganic glues can cause aggregation in some environments, it is clear that biologic processes

72 and their attendant organic glues dominate aggregate formation." Abiotic mechanisms are

73 expected to primarily form microaggregates, which may require more time than macroaggregates

74 to develop but persist longer in the environment (Tisdall and Oades, 1982; Lützow et al., 2006).

75 The most important abiotic mechanisms that bind soil aggregates are generally considered to be

76 ligand exchange and polyvalent cation bridging (Six et al., 2004; Bronick and Lal, 2005; Keil

77 and Mayer, 2014). Ligand exchange dominates in acidic soils because of abundant oxides.

78 Acidic hydroxyl groups of organic matter are exchanged with hydroxyl groups on mineral oxide

79 surfaces and cemented into place, thus creating water-stable connection points within aggregates.

80 Cation bridging — typically involving calcium, magnesium, or aluminum — dominates in neutral

81 and basic soils. Positively charged cations can connect soil particles by bridging the gap between

82 negatively charged clay surfaces and negatively charged organic compounds (Oades, 1988;

83 Muneer and Oades, 1989; Clarholm et al., 2015). If enough connections are made, then a water-

84 stable aggregate is formed. Although drying-rewetting cycles are known to form aggregates (Six 
85 et al., 2004), water's role in promoting abiotic "bridging reactions" is largely unknown because 86 of the confounding influences of biology.

Beneficial effects of biology on soil aggregate stability are well-documented (Oades,

88 1993; Tisdall, 1994; Degens, 1997; Six et al., 2004). Plants play two main roles in the formation

89 of soil aggregates, particularly macroaggregates (Denef et al., 2001). First, plant roots physically

90 enmesh soil into aggregates (Tisdall and Oades, 1982; Oades and Waters, 1991; Degens, 1997;

91 Six et al., 2004). Reflecting this, root length and plant abundance can relate positively to

92 aggregate stability (Roberson et al., 1991; Haynes and Francis, 1993). Second, plants affect

93 aggregate formation through organic residues that enter the soil (e.g., litterfall, root sloughing

94 and dieback) and mix with mineral particles. These residues can act as a "nucleus" for aggregate

95 formation by feeding microbes that secrete organic glues (De Gryze et al., 2005; Cosentino et al.,

96 2006). Although the qualitative roles of plants are well known, their quantitative role is lesser

97 known, particularly in seasonally dry ecosystems.

Microbes - whether they are inside macroinvertebrates or exist as free-living bacteria and

99 fungi - also engineer soil aggregates. Soil microbial biomass relates positively to aggregate

100 formation (Degens, 1997; Keim and Kandeler, 1997; Ghani et al., 2003; Cosentino et al., 2006),

101 a pattern explained by two mechanisms. First, fungi are known to enmesh aggregates similarly to

102 plant roots (Tisdall and Oades, 1982), particularly in sandy soils (Chenu, 1989; Chantigny et al.,

103 1997; De Gryze et al., 2005). Removing fungi using fungicide reduces macroaggregate

104 formation (Denef et al., 2001). Second, bacteria and fungi produce extracellular polymeric

105 substances (EPS) that act as glues to connect soil aggregates as a possible strategy for accessing

106 distant resources and creating a more stable environment in which to live (Roberson and

107 Firestone, 1992; Chenu and Roberson, 1996; Flemming and Wingender, 2010). Microbes on the 
outer surface of aggregates may be in an ideal location to connect neighboring aggregates if they can access C substrates to make EPS (Holden, 2011; Schimel and Schaeffer, 2012). Production of EPS is likely a deeply rooted life-history trait of microbes used to remain hydrologically connected to resources in dry soil (Schimel and Schaeffer, 2012). Although EPS have been studied for the past five decades (e.g., Cheshire, 1977; Foster, 1981), extracting and purifying microbial EPS from soil is still not straightforward (Redmile-Gordon et al., 2014).

The first goal of our study was to investigate plant growth and $\mathrm{C}$ input as a driver of soil aggregate stability in a seasonally dry grassland. Although much has been learned in the laboratory, there is a lingering need to identify mechanisms that form and preserve water-stable aggregates in field soils (Degens, 1997). To quantify the legacy of fresh C inputs on soil aggregate stability, our approach was to create a gradient of plant influence by continuously removing grasses and forbs. Do plant $\mathrm{C}$ inputs during the growing season sustain water-stable aggregates through the dry season? And do plant-aggregate interactions depend on the length of the dry season? We expected that water addition (i.e., no dry season) would accelerate the decomposition of plant binding agents and therefore decrease the average size of water-stable aggregates, particularly when combined with plant removal.

Our second goal was to quantify the contribution of microbes to macroaggregate formation on the drier side of the soil moisture spectrum. Previous experiments to separate biotic and abiotic mechanisms have been hampered by the need to add sterilant dissolved in water (Molope et al., 1987; Hu et al., 1995; Bossuyt et al., 2001; Denef et al., 2001), thus preventing conclusions about dry soil. We instead fumigated with chloroform $\left(\mathrm{CHCl}_{3}\right)$ vapor to continuously kill microbes without water. By separating biotic and abiotic processes on the drier side of the soil moisture spectrum, we gain a clearer understanding of whether microbes help 
131 engineer dry soil and whether effects of biotic and abiotic processes are additive. We

132 hypothesized that the combination of ample access to substrates and strong incentive to increase

133 hydrologic connectivity causes microbes to allocate more $\mathrm{C}$ to soil binding agents at intermediate

134 moisture (i.e., moderate stress).

135

136 2. Materials and methods

137 2.1. Site description

138 We studied a seasonally dry grassland at the University of California Sedgwick Reserve 139 near Santa Ynez, California, USA (370 m ASL, $\left.34.7120^{\circ} \mathrm{N}, 120.0388^{\circ} \mathrm{W}\right)$. The site experiences

140 a Mediterranean-Type climate with hot dry summers and cooler wet winters. The mean annual

141 precipitation and temperature are $380 \mathrm{~mm}$ and $16.8^{\circ} \mathrm{C}$, respectively. Roughly $90 \%$ of annual

142 precipitation falls between November and April. The Water Year (WY) officially begins on 1

143 October and ends on 30 September. During the 2 y of the study, annual precipitation was roughly

$14450 \%$ below average (175 mm in WY 2013 and $201 \mathrm{~mm}$ in WY 2014).

The soil was keyed as a thermic Pachic Haploxeroll with silty clay loam texture, pH 6.0,

$1462.2 \% \mathrm{C}$, and $0.21 \% \mathrm{~N}$. The soil is derived from the Paso-Robles formation, which is poorly

147 consolidated alluvial material formed from montmorillinite that eroded from nearby Monterey

148 Shale deposits, hence the prevalence of 2:1 clays. The soil also contains some amount of

149 Franciscan Complex minerals including ultramafics (e.g., serpentinite), sandstone, and chert.

150 Vegetation is dominated by nonnative Mediterranean annual grasses; primarily Bromus

151 diandrus, Bromus hordaceous, and Avena fatua.

152

153 


\subsection{Field treatments}

\subsubsection{Plant $\mathrm{C}$ input}

To create a gradient of plant influence (i.e., both direct effects of root enmeshment and indirect effects of labile $\mathrm{C}$ input), grasses and forbs were removed by hand as soon as possible after germination continuously for $2 \mathrm{y}$. Plots $(2 \mathrm{~m}$ by $1 \mathrm{~m})$ were selected in December 2012 based on similar initial plant cover and composition; plots were seggregated into three blocks and all treatments were replicated in each block. The site was relatively flat $(<2 \%$ grade) to minimize lateral flow of water and dissolved $\mathrm{C}$ between treatments. All plots were oriented with the longer 2-m side spanning from north to south and marked at the corners with stakes. Plots were spaced at least $1 \mathrm{~m}$ apart to minimize edge effects and "sharing" of water between plots.

To manipulate plant C input, we began on 14 December 2012 by removing all existing plant litter (i.e., thatch) from the soil surface gently by hand. Thatch removal was done to minimize any confounding effects of older litter so that each treatment would have similar initial conditions. Based on a comparison with additional plots where thatch was not removed, there was not a statistically significant effect of thatch removal on soil water content $(0-10 \mathrm{~cm}$ deep) or temperature $(5 \mathrm{~cm}$ deep) during the dry season $(P>0.05)$.

We created four levels of plant removal: $0 \%, 30 \%, 60 \%$, and $90 \%$. For the $0 \%$ plant removal treatment, plots were not altered after the initial thatch removal. For the $30 \%$ plant removal treatment, roughly one-third of the aboveground biomass was gently weeded by hand to minimize soil disturbance. Roots were removed too if they easily slid out of the ground without disturbing soil. To achieve $30 \%$ plant removal, the 2-m side of the plot was divided into six 33cm sections with each section roughly equal to three hand-widths. In a random, curvy fashion, one hand-width of plants was pulled from each section, resulting in roughly a one-third removal of aboveground biomass across the entire plot. For the $60 \%$ plant removal treatment, two hand- 
178 widths of plants were pulled from each section, resulting in roughly a two-third removal of 179 aboveground biomass. For the $90 \%$ plant removal treatment, we tried to remove all plants.

180 However, we refrain from referring to the treatmeant as " $100 \%$ removal" because of germination 181 between site visits. The plant removal treatments were maintained every $7-10$ days during the 182 growing season and as needed during the dry season. Plant removal during the dry season was 183 needed when wind blew litter onto plots and when plants germinated prematurely in the irrigated 184 plots. However, premature germination during summer was surprisingly rare. Our goal was to 185 alter plant $\mathrm{C}$ input during the growing season, but not to extend the length of the growing season. 186 Edge effects of root growth from outside the plots were minimized by clearing a $\sim 30-\mathrm{cm}$ 187 perimeter around every plot using a motorized weed whacker and garden sheers. The plant C 188 treatments were maintained through the end of WY 2014.

\subsubsection{Dry season length}

The four levels of plant $\mathrm{C}$ input were crossed with two levels of dry season length $(\mathrm{N}=$

192 3). The dry season in California typically lasts six months; from May until October. For the 193 purpose of assessing plant effects on water-stable aggregates, we aimed to compare the extremes 194 of water availability: extended dry season vs. no dry season. The dry season length was extended 195 until January (i.e., $\sim 9$ months total) using rainout shelters $(2.5 \mathrm{~m}$ by $1.2 \mathrm{~m})$ that intercepted all 196 water before it reached the soil. Each shelter was built from clear corrugated polycarbonate roof 197 panels (Suntuf, Palram Americas, Kutztown, Pennsylvania) attached to a metal frame with two 198 support legs on the higher corners. The higher side of the shelter $(\sim 30 \mathrm{~cm}$ tall $)$ was oriented on 199 the east side of the plot and the water drained to the lower, west side ( $\sim \mathrm{cm}$ tall). Each shelter 200 was secured in the plot using metal rebar at the corners. Probably because the shelters were 
201 sufficiently ventilated at the sides (i.e., the 1-m side of the plots), we did not observe any

202 consistent effect of the shelters on soil temperature (e.g., greenhouse effect) or soil moisture

203 (e.g., dew accumulation). To extend the WY 2013 dry season, shelters were in place from 7

204 October 2013 (one week before the first rain event) until 30 January 2014.

205

The "no-dry-season" treatment was designed to prevent severe micro-scale hydrologic

206 disconnectivity during the typical 6-month dry season (Parker and Schimel 2011). The

207 predetermined threshold between "moist" and "dry" soil was $10 \%$ volumetric water content

208 (VWC), equivalent to approximately 9\% gravimetric water content and -10 MPa water potential

209 (Priester et al., 2013). Based on previous measurements near our site (Fierer et al., 2005), 10\%

210 VWC is associated with a marked decline in soil respiration, suggesting that microbes rapidy

211 lose access to $\mathrm{C}$ substrates as soils dry below this water content; consistent with the $-14 \mathrm{MPa}$

212 threshold for diffusion determined by meta-analysis (Manzoni et al., 2012). Therefore, we

213 eliminated the dry season for 2 y by irrigating plots roughly biweekly, starting as soon as soils

214 reached the $10 \% \mathrm{VWC}$ threshold in the spring. Irrigation continued until the first rain event in

215 the fall. In 2013, irrigation began on 14 May and lasted until 6 November with a total of twelve

216 irrigation events. In 2014, irrigation began on 23 May and lasted until 21 October with a total of

217 ten irrigation events. Each irrigation event consisted of adding $30 \mathrm{~L}$ of local well water to each

218 plot using a backpack sprayer with a nozzle to minimize soil disturbance. This amount of water

219 was equivalent to $1.5 \mathrm{~cm}$ per plot per irrigation event. Because of the sprayer's $15 \mathrm{~L}$ capacity and

220 the desire to allow time for infiltration, the $30 \mathrm{~L}$ water was added in two $15 \mathrm{~L}$ "doses" spaced

221 roughly $1 \mathrm{~h}$ apart. Based on field measurements of soil moisture using a portable MiniTrase

222 Time Domain Reflectometer (Soil Moisture Equipment Corporation, Santa Barbara, California),

223 each irrigation event moistened soils in the top $10 \mathrm{~cm}$ to $\sim 25 \% \mathrm{VWC}$. Then, on average, soils 
224 dried 1\% VWC per day, particularly during the middle of the summer when temperatures soared

225 and winds gusted. Thus, irrigation was required every 2 weeks to prevent drying below $10 \%$

226 VWC. Because this study was performed during a severe multiyear drought, it should be noted

227 that the $180 \mathrm{~mm}$ of total water added in 2013 and $150 \mathrm{~mm}$ in 2014 nearly doubled annual

228 precipitation.

229

230

\subsection{Field measurements to assess plant controls}

\subsubsection{Soil sampling}

Surface soils $(0-10 \mathrm{~cm})$ were collected from field plots on 30 January 2014 and 9

233 September 2014. On the first date after $1 \mathrm{y}$ of treatments, soils were only sampled from the long-

234 dry-season treatment (across all levels of plant removal) to assess the legacy effect of plants on

235 soil structure after 9 months without precipitation. On the second date after 2 y of treatments,

236 soils were sampled from both the long-dry-season and no-dry-season treatments to assess the

237 persistence of plant effects and the role of soil moisture.

On both dates, we collected one 5-cm diameter soil core from near the center of each

239 plot. Due to the hardness of dry soil, a steel corer and sledgehammer were required to extract the

240 soils, but we tried to minimize disturbance to soil structure by hammering as few times as

241 possible and by gently sliding the soil out of the corer. Soil cores were transferred to individual

242 sealed plastic containers that were rigid to prevent disturbance to soil structure during transport

243 to the laboratory at the University of California Santa Barbara. Field moist soils were first sieved 244 to $<9.5 \mathrm{~mm}$ to remove large rocks. Any visible plant leaves, stems, or roots were removed by 245 hand. Soil clods and aggregates $>9.5 \mathrm{~mm}$ were gently broken along natural planes of weakness 246 and then passed through the sieve. Soils were then stored at room temperature $\left(20-22{ }^{\circ} \mathrm{C}\right)$ and 
247 air dried for 2 weeks to create a similar starting point before rewetting. This was particularly

248 important in September 2014 when we compared dry soils to irrigated soils.

252 according to Elliott (1986). Air-dried soils $(<9500 \mu \mathrm{m})$ were gently mixed with a spoon and a 253 representative subsample was weighed ( $40 \mathrm{~g}$ ) into sealed specimen cups until sieving. The soil in 254 each cup was gently poured and spread across a $2000 \mu \mathrm{m}$ sieve that was placed inside a larger 255 circular plastic tub to hold water. Slaking — or the breakdown of soil aggregates by air pressure 256 buildup - began by slowly pouring deionized water into the plastic tub (i.e., not directly onto the 257 sieve) to gently rewet the aggregates from the bottom-up. Enough water was added to completely 258 submerse all aggregates on the sieve. Aggregates were left undisturbed to slake for $5 \mathrm{~min}$ before 259 the sieve was manually moved up and down $3 \mathrm{~cm}, 50$ times for 2 min to allow smaller 260 aggregates to fall through the sieve into the plastic tub. The aggregates that remained on the 261 sieve were gently transferred to a clean, pre-weighed alumimum pan using a squeeze bottle with 262 deionized water. The soil solution that passed through the $2000 \mu \mathrm{m}$ sieve was then gently poured 263 onto a $250 \mu \mathrm{m}$ sieve in a second plastic tub, and the 2 min wet-sieving procedure was repeated.

264 The fraction of aggregates between $250 \mu \mathrm{m}$ and $2000 \mu \mathrm{m}$ was transferred to a separate aluminum 265 pan. Finally, the soil solution that passed through the $250 \mu \mathrm{m}$ sieve was poured onto a $53 \mu \mathrm{m}$ 266 sieve and the 2 min wet-sieving procedure was repeated. All sieves and tubs were thoroughly 267 brushed and rinsed with water between samples. The soil fractions between $53 \mu \mathrm{m}$ and $250 \mu \mathrm{m}$ 268 and $<53 \mu \mathrm{m}$ were transferred to separate aluminum pans. Water was evaporated from the aggregates by placing the four pans from each soil sample into a drying oven at $60^{\circ} \mathrm{C}$ for $72-96$ 
270 h. After drying, any remaining rocks and plant litter were removed from the largest size class

271 using forceps. By subtracting the pan weight from the oven-dry soil in the pan, we calculated the

272 percentage of soil in different size classes. We henceforth refer to water-stable aggregates greater

273 than $2000 \mu \mathrm{m}$ diameter as "large macroaggregates." Aggregates between $250 \mu \mathrm{m}$ and $2000 \mu \mathrm{m}$

274 are "small macroaggregates" and between $53 \mu \mathrm{m}$ and $250 \mu \mathrm{m}$ are "microaggregates." Particles <

$27553 \mu \mathrm{m}$ are referred to as "clay and silt."

276

277

278

279

280

281

\subsubsection{Complementary belowground measurements}

To characterize the efficacy of the plant removal treatment as well as field patterns of C and $\mathrm{N}$ availability and initial conditions for the 6-month laboratory experiment, we measured soil volumetric water content, plant root biomass, soil $\mathrm{C}$ and $\mathrm{N}$ pools, and soil microbial biomass.

Soil volumetric water content (VWC) was monitored 0 - $10 \mathrm{~cm}$ deep using a portable

282 MiniTrase Time Domain Reflectometer (Soil Moisture Equipment Corporation, Santa Barbara, 283 CA) with stainless steel waveguides. On 24 sampling dates between 12 March 2013 and 22

284 September 2014, the waveguides were inserted into the soil in the center of each plot between

285 10:00 and 12:00. The irrigated plots (i.e., no dry season treatment) were typically measured one

286 week after water addition in 2013 and two weeks after water addition in 2014. Thus, the

287 measurements of soil moisture in the no-dry-season treatment represent the drier extent of 288 conditions experienced in these plots.

289 Root biomass was measured using wet-sieving (Fogel, 1983). Intact soil cores (5 cm 290 diameter, $10 \mathrm{~cm}$ deep) were collected from all plant removal treatments $(\mathrm{N}=3)$ at the end of the 291 first growing season on 24 May 2013. In the laboratory, we first weighed each soil core and then 292 subsampled $(10 \mathrm{~g})$ to calculate and correct for soil water content. The remaining soil was gently 
transferred to a $1 \mathrm{~L}$ canning jar. Enough deionized water was added to the beaker to completely cover the soil $(\sim 300 \mathrm{ml})$. The jar was sealed with a lid and placed on a rotary shaker table at 180 rpm for 5 min to gently separate roots from mineral soil. After shaking, mineral soil was allowed to settle for 5 min while roots and other organic matter floated to the top. The floating material was then poured onto a $500 \mu \mathrm{m}$ sieve and gently rinsed with water using a squeeze bottle. Using forceps, all root fragments were transferred from the sieve to a clean, pre-weighed aluminum pan. The remaining soil in the jar was shaken and sorted for two additional cycles to extract as many roots as possible. Any organic matter that was not obviously a root was not transferred to the pan. Pans were dried at $60^{\circ} \mathrm{C}$ for $48 \mathrm{~h}$ to calculate the dry weight of roots in each core. Root biomass was expressed as $\mathrm{mg} \mathrm{g}^{-1}$ soil.

Soil $\mathrm{C}$ and $\mathrm{N}$ availability in $0 \%$ and $90 \%$ plant removal plots (long-dry-season treatment only) was estimated in January 2014 using three approaches. First, total C and N concentrations in oven-dried soils were measured using an elemental combustion system (NA 1500 Series 2, Fisons Instruments, Ipswich, United Kingdom). Second, water-extractable C (organic) and N (inorganic and organic) were measured by shaking $(180 \mathrm{rpm}) 8 \mathrm{~g}$ of soil in $32 \mathrm{ml}$ of deionized water in a 50-ml centrifuge tube for $3 \mathrm{~h}$. After shaking, the tubes were centrifuged $(3000 \mathrm{~g}, 15$ min) and the supernatant $(10 \mathrm{ml})$ was pipetted into a clean $12-\mathrm{ml}$ centrifuge tube and stored at $20^{\circ} \mathrm{C}$ until analysis on a total organic carbon analyzer (TOC-V CSN, Shimadzu Scientific Instruments, Columbia, Maryland). Finally, the most labile pool of soil $\mathrm{C}$ was estimated by the respiration rate following rewetting. In a 125-ml canning jar equipped with an airtight butyl rubber septum, $10 \mathrm{ml}$ of deionized water was added to $5 \mathrm{~g}$ of soil and the slurry was shaken (180 rpm) for $2.5 \mathrm{~h}$. The headspace carbon dioxide $\left(\mathrm{CO}_{2}\right)$ concentration was measured $0.5,1.5$, and $2.5 \mathrm{~h}$ after adding water. Each gas sample $(1 \mathrm{ml})$ was collected using a glass syringe with side- 
316 port needle, and then immediately measured using a non-dispersive infrared gas analyzer (LI-

317 820, LiCor, Inc., Lincoln, Nebraska). Rates of $\mathrm{CO}_{2}$ production were expressed as $\mu \mathrm{g} \mathrm{CO}_{2}-\mathrm{C}$ per

318 gram of oven-dry soil equivalent per hour.

319 Soil microbial biomass was compared across field and laboratory treatments by substrate-

320 induced respiration (Anderson and Domsch, 1978). Because we used glucose as the sole

321 substrate, this assay is henceforth referred to as "glucose-induced respiration." The procedure for

322 glucose-induced respiration was almost identical to the wet-up respiration assay described in the

323 previous paragraph. The only difference was that a glucose solution (50 $\mathrm{mg}$ glucose dissolved in

$3241 \mathrm{ml}$ ultrapure water) was added to the soil slurry before sealing the jars. The amount of glucose

325 added (10 $\mathrm{mg} \mathrm{g}^{-1}$ soil) was based on an optimum found by West and Sparling (1986). Glucose is

326 known to be a straightforward indicator of biological activity in this soil (Blankinship et al.,

327 2014).

328

329

2.4. Laboratory experiments to assess microbial mechanisms

To separate biotic and abiotic mechanisms that form water-stable macroaggregates, we manipulated microbial biomass and soil moisture in the laboratory. The first experiment lasted

332 six months to simulate the length of a typical dry season, allowing ample time for aggregate

333 formation (e.g., De Gryze et al., 2005). The second follow-up experiment lasted one week to see 334 how quickly the treatment effects appeared.

\subsubsection{Long-term sterilized soil incubations}

We began by collecting soils $(0-10 \mathrm{~cm})$ on 30 January 2014 from the long-dry-season

treatment, both in plots with plants (0\% removal) and without plants (90\% removal). Soils from 
all the plots with plant $\mathrm{C}$ input were combined and homogenized to create a single composite sample. Similarly, all soils without recent plant $\mathrm{C}$ input were combined and homogenized. The two composite samples were sieved $(9.5 \mathrm{~mm})$ and air-dried in the laboratory for two weeks to normalize any differences in soil moisture. Large rocks and roots were removed by hand.

To quantify macroaggregate formation, soil incubations began with only microaggregates and other particles (i.e., silt and clay) with a diameter less than $250 \mu \mathrm{m}$. Dry-sieving was first used to separate the $<250 \mu \mathrm{m}$ fraction. The $>250 \mu \mathrm{m}$ fraction (i.e., macroaggregates) was disaggregated using a coffee grinder ( $\sim$ min per sample) and then shaken through the $250 \mu \mathrm{m}$ sieve. The grinding efficiency was roughly $90 \%$ (i.e., $~ 10 \%$ of macroaggregates could not be disaggregated). Soil subsamples $(\mathrm{N}=3)$ from both treatments were used to measure initial levels of gravimetric water content, water-extractable organic $\mathrm{C}$, and microbial biomass. For six months, soils were exposed to all combinations of three treatments $(\mathrm{N}=3)$ : fresh C input (with vs. without plants); moisture (5\%, 10\%, 15\%, 20\% of water-holding capacity); and microbial biomass (live vs. sterile). The water-holding capacity (WHC) of ground soil was 0.75 $\mathrm{g} \mathrm{H}_{2} \mathrm{O} \mathrm{g}^{-1}$ soil, as measured by saturation on Whatman Grade 1 filter paper followed by $24 \mathrm{~h}$ of draining under $100 \%$ humidity. A soil water content of $5 \% \mathrm{WHC}$ is typical during the summer dry season and 20\% WHC is typical during the winter wet season; $10 \%$ and $15 \%$ WHC represent the intermediate drying phase during spring. Ground air-dry soils $(<250 \mu \mathrm{m})$ at $5 \% \mathrm{WHC}$ were weighed (45 g) into 50-ml glass beakers. The depth of soil in each beaker was $\sim 4 \mathrm{~cm}$. For the $10 \%, 15 \%$, and $20 \%$ WHC treatments, deionized water was added using a spray bottle with a fine mist. Our aim was to gently rewet the soil while vertically distributing the water as evenly as possible. The $45 \mathrm{~g}$ soil subsample was added as four $\sim 11.25 \mathrm{~g}$ layers (gently agitating the beaker to level soil between layers) with a certain number of sprays $\left(\sim 0.1 \mathrm{~g} \mathrm{H}_{2} \mathrm{O}\right.$ per spray) preceding 
each layer. For the 10\% WHC treatment, there were four sprays per layer (i.e., 16 sprays total). For 15\% WHC, there were eight sprays per layer (32 sprays total). For 20\% WHC, there were 12 sprays per layer (48 sprays total). Based on visual observation, the discrete layers of water diffused and disappeared within one week. After manipulating soil moisture, each beaker was immediately placed into individual $1 \mathrm{~L}$ canning jars and sealed with airtight lids to prevent drying. The $10 \%, 15 \%$, and $20 \%$ WHC treatments also included $5 \mathrm{ml}$ of additional water that was pipetted to the bottom of the jar (i.e., outside of the beaker) to maintain $100 \%$ humidity in the jar to minimize evaporation from the soil during the incubation. Our intent was to investigate discrete, constant levels of soil moisture rather than rewetting cycles.

To kill soil microbes without adding water, half of the incubation jars were continuously fumigated with ethanol-free chloroform $\left(\mathrm{CHCl}_{3}\right)$. In contrast to the continuous sterilization of $\mathrm{CHCl}_{3}$ vapor, other common sterilants (e.g., sodium azide, mercuric chloride, Captan fungicide, and oxytetracycline bactericide) must be added in combination with water and may also require repeated applications to prevent microbial regrowth. In a fume hood, the jars assigned to the sterilized treatment were opened and a $12 \mathrm{ml}$ vial with $\mathrm{CHCl}_{3}$ was carefully placed inside next to the beaker. The jars were then sealed using lids with Teflon tape wrapped around the rubber seal to prevent corrosion. Using a vacuum pump, we evacuated each jar and allowed air to rush back in to enhance $\mathrm{CHCl}_{3}$ movement into soil micropores.

The jars were incubated in a vented, temperature-controlled room in the dark for six months at $30^{\circ} \mathrm{C}$. This temperature is common during the dry season in surface soils at our field site. Jars in the live treatment were vented weekly to prevent $\mathrm{CO}_{2}$ buildup and oxygen depletion. Jars in the sterilized treatment, which are known to have very low rates of $\mathrm{CO}_{2}$ production (Blankinship et al., 2014), were vented monthly in the fume hood and refilled with fresh $\mathrm{CHCl}_{3}$ 
385 as needed. At the end of the six months, we vented the jars, wiped off excess water on the

386 outside of the beaker, and recorded the final weight of each beaker of soil to ensure proper

387 gravimetric water content. Using a spatula, a $5 \mathrm{~g}$ subsample was carefully scraped off the top

388 corner of the soil in the beaker and immediately $(<1 \mathrm{~h})$ used to estimate microbial biomass by

389 glucose-induced respiration, as described earlier. The remaining soil ( $40 \mathrm{~g}$ dry weight) was

390 placed in a drying oven at $60{ }^{\circ} \mathrm{C}$ for $16 \mathrm{~h}$ to quickly dry soils before aggregate separation. For the 391 aggregate separation procedure, it is important that all soils begin at a similar, dry state so that

392 the air pressure buildup is comparable following rewetting (Haynes and Beare, 1997). Previous

393 tests showed that $16 \mathrm{~h}$ was a sufficient amount of time to dry soils from all moisture treatments.

394 The goal was to maximize the drying rate in order to minimize any microbial regrowth after

$395 \mathrm{CHCl}_{3}$ removal. After recording the dry soil weight, a fine scalpel was used to gently transfer

396 and spread soil from the beaker onto a $250 \mu \mathrm{m}$ sieve. Water-stable macroaggregates that

397 remained on the sieve after 5 min of slaking and 2 min of wet-sieving were transferred to

398 aluminum pans, dried, and weighed as described earlier. We calculated the percentage of soil

399 mass that was incorporated into water-stable macroaggregates. Because our aim was to quantify

400 the formation of macroaggregates from microaggregates, silt, and clay, we did not distinguish

401 between large $(>2000 \mu \mathrm{m})$ and small macroaggregates $(250-2000 \mu \mathrm{m})$ in the laboratory

402 experiment.

403

2.4.2. Short-term sterilized soil incubations

405

Results from the 6-month incubations motivated a shorter-term, follow-up experiment to

406 see how quickly the effects of water and microbes appear. Is it really necessary to run an

407 incubation for 6 months to observe the formation of macroaggregates by water and microbes? 
408 The procedure for the short-term incubations was the same as for the long-term incubations, 409 except that: (i) incubations lasted one week; (ii) soils were collected on 9 September 2014; and

410 (iii) only soils from plots with plants were included.

$412 \quad$ 2.5. Aggregate imaging

413 We imaged aggregates after seeing differences in the shape of biotically and abiotically

414 formed aggregates with the naked eye. Macroscopic images of oven-dried water-stable

415 aggregates were captured using a point-and-shoot camera (PowerShot ELPH 310 HS, Canon

416 Inc., Tokyo, Japan). Microscopic images were captured using an Environmental Scanning

417 Electron Microscope (ESEM) at the Micro-Environmental Imaging and Analysis Facility at

418 University of California Santa Barbara. The system included an XL30 ESEM (FEI Company,

419 Hillsboro, Oregon) with field emission gun, patented gaseous secondary electron detector, and

420 temperature-controlled Peltier stage to control condensation (400 Pa). We imaged air-dry, water-

421 stable macroaggregates isolated from fresh soils collected on 2 February 2015 in plots with and

422 without plants $(\mathrm{N}=4)$. We also imaged air-dry and rewetted biogenic (live, $10 \%$ WHC) and

423 physicogenic (sterilized, 20\% WHC) macroaggregates isolated at the end of the laboratory

424 incubations $(\mathrm{N}=4)$.

425

426 2.6. Statistical analyses

427 The mean weight diameter for each soil sample was calculated by multiplying the mean

428 diameter of each size class $(5750,1125,151.5$, and $26.5 \mu \mathrm{m})$ by the proportion of soil mass in

429 each size class and then adding the four products. JMP 12 software (SAS Institute, Cary, North

430 Carolina) was used for all statistical tests. Effects of field plant removal on aggregate size were 
431 analyzed using both linear regression (with four levels of plant removal on $x$-axis) and pooled $t$ -

432 tests at an alpha level of 0.05 to compare plots with plants ( $0 \%$ removal) to plots without plants

433 (90\% removal). No transformations were required. Effects of soil moisture in the laboratory were

434 identified using Tukey HSD post hoc tests at an alpha level of 0.05 for each combination of

435 microbial biomass and plant removal treatments.

437 3. Results

438 3.1. Effects of plant removal: field experiment

439 Removing 1 year of plant growth caused an $87 \%$ decrease in root biomass, $35 \%$ decrease

440 in the respiration pulse upon rewetting, and four-fold increase in water-extractable N (Table 1).

441 Root biomass in the $30 \%$ and $60 \%$ plant removal plots was $1.9( \pm 0.8)$ and $1.3( \pm 0.6) \mathrm{mg} \mathrm{g}^{-1}$

442 soil, respectively, which was intermediate to the $0 \%$ and $90 \%$ plant removal plots, but more

443 similar to $90 \%$ removal. Soil moisture was similar between the $0 \%, 30 \%$, and $60 \%$ plant removal

444 treatments; but soils in the $90 \%$ plant removal treatment tended to be wetter during the dry

445 season, particularly early in the dry season and in 2013 (Fig. 1). In 2014, all plant growth was

446 stunted by the lack of late-fall and early-winter precipitation. In a one-way ANOVA, statistically

447 significant differences $(\mathrm{P}<0.05)$ between $0 \%$ and $90 \%$ plant removal lasted from 22 March until

4482 July in 2013, and from 5 May until 5 June in 2014. Statistically significant differences in soil

449 moisture between the long dry season and no dry season treatments lasted from 24 May until 18

450 December in 2013 and from 5 June until 22 September in 2014. There was not a statistically

451 significant effect of plant removal on soil microbial biomass (as estimated by glucose-induced

452 respiration), total water-extractable organic $\mathrm{C}$, or total $\mathrm{C}$ and $\mathrm{N}$. 
Removing plants reduced the average size of water-stable soil aggregates by $22-33 \%$

454 regardless of dry season length or duration of plant removal (Fig. 2). All linear regressions of

455 plant removal and the mean weight diameter of soil aggregates were statistically significant $(\mathrm{P}<$

456 0.05). The negative effect of plant removal on the average size of water-stable aggregates was

457 primarily driven by a shift from large macroaggregates to small macroaggregates and

458 microaggregates (Fig. 3). This pattern did not depend on dry season length. In the long-dry-

459 season plots, 2 years of plant removal decreased the soil mass in large macroaggregates by

$46013.1 \%$, which was redistributed into small macroaggregates $(+7.3 \%)$, microaggregates $(+4.5 \%)$,

461 and the silt and clay fraction $(+1.3 \%)$. In the no-dry-season plots, plant removal decreased the

462 fraction of large macroaggregates by $23.1 \%$, which was primarily distributed into small

463 macroaggregates $(+18.1 \%)$, but also microaggregates $(+3.4 \%)$ and silt and clay $(+1.6 \%)$.

464

Large macroaggregates collected late in the dry season from plots with plants generally

465 showed larger pores than plots without plants (Fig. 4). Also, the binding effects of dead roots and

466 fungal hyphae were easy to find when plants were present. In plots without plants, however, we

467 did not observe any obvious plant-derived detritus in macroaggregates.

468

469 3.2. Effects of microbe removal: lab experiment

470 After six months of continuous $\mathrm{CHCl}_{3}$ fumigation in the laboratory, soil microbial

471 biomass (as estimated by glucose-induced respiration) in the sterilized treatment was $82-99 \%$

472 lower than the live treatment without $\mathrm{CHCl}_{3}$, regardless of soil moisture or plant treatments (Fig.

473 5). In the sterilized treatment, water-stable macroaggregate formation increased with increasing

474 soil moisture, both after six months (Fig. 6) and one week (Fig. 7). After one week, an average of

$4750.5 \%$ of soil mass was incorporated into macroaggregates under the driest condition and $2.5 \%$ 
476 under the wettest condition. After six months, $0.4 \%$ of soil mass was incorporated into water-

477 stable macroaggregates under the driest condition and $23 \%$ of soil mass under the wettest

478 condition. The effect of moisture did not depend on recent plant $\mathrm{C}$ input.

479 In the live treatment, macroaggregate formation after six months was greatest in soils at 480 intermediate moisture (Fig. 6). Regardless of plant removal, 12-17\% of soil mass was

481 incorporated into macroaggregates under intermediate soil moisture, representing a 13-fold

482 increase compared to sterilized soil at 10\% WHC and a two-fold increase compared to sterilized

483 soil at $15 \%$ WHC. Under the driest condition (i.e., 5\% WHC), macroaggregate formation in the

484 live treatment was similar to the sterilized treatment. Under the wettest condition (i.e., $20 \%$

485 WHC), however, macroaggregate formation declined by $75 \%$ in the live treatment as compared

486 to the sterilized treatment. The 1-week follow-up experiment showed very little macroaggregate

487 formation in the live treatment, with a slight increase from $0.5 \%$ of soil mass under the driest

488 condition to $0.8 \%$ under the wettest condition.

489 The macroaggregates that formed when soil was sterile and moist were visually distinct

490 from macroaggregates formed when soil was live and dry, both at macro- and micro-scales (Fig.

491 8). The large macroaggregates formed under sterile conditions - henceforth referred to as

492 physicogenic aggregates — tended to be flat with jagged, angular edges. These physicogenic

493 aggregates showed stacks of silt and microaggregates with a greater prevalence of angular micro-

494 structures and fewer spherical micro-structures. The macroaggregates formed under live

495 conditions - henceforth referred to as biogenic aggregates - tended to be spherical with rounded

496 edges. These biogenic aggregates showed a greater prevalence of spherical micro-structures and

497 generally larger pores. 


\section{Discussion}

By systematically removing plants and microbes, we aimed for a more integrative understanding of the biotic and abiotic processes that form and preserve water-stable aggregates on the drier side of the soil moisture spectrum. The gradient of plant removal in the field allowed us to quantify the role of plants in preserving water-stable aggregates. At the same time, sterilizing soils in the laboratory allowed us to determine the role of microbes in forming macroaggregates compared to abiotic processes alone.

Plants were important for stabilizing large macroaggregates; the plots without plants had a lower proportion of large macroaggregates despite being wetter on average. We are uncertain why the mean weight diameter of aggregates was larger in the second year of the field study; perhaps this was because the first year had less precipitation overall and an extremely dry second half of the growing season which may have stunted the growth of soil macroaggregates. We did not measure root or aboveground plant biomass in both years, so we cannot confirm this mechanism. Without summer irrigation, soil lost from the large macroaggregates tended to distribute evenly into small macroaggregates and microaggregates. With irrigation, soil lost from large macroaggregates was primarily distributed into small macroaggregates. Therefore, plantsdirectly or indirectly — appear to have connected small macroaggregates to make large macroaggregates. However, at least after two years, there was little evidence that fewer small macroaggregates formed, suggesting that microbes and abiotic processes played a stronger role than plants in stabilizing small macroaggregates. We did not sample the field treatments often enough to characterize seasonal variation in aggregate size, but we can reasonably assume that few aggregates were formed during the middle and later parts of the dry season when plants were dead and microbes were hydrologically disconnected from their resources. The aggregates we 
522 isolated late in the dry season were likely formed during the previous wet season and spring dry-

523 down period. Our results indicate that dead, plant-associated binding agents — primarily roots-

524 persist through the dry season, probably because the binding agents were physically inaccessible

525 to other microbial decomposers. The chemical resources and physical soil structure that plants

526 depend on during wet periods can be sustained during dry periods. Therefore, at least in the field,

527 the legacy of dead plants on soil structure was greater than we expected.

529 than weakened. We hypothesized that water addition would accelerate decomposition of plant

530 binding agents and therefore decrease the average size of water-stable soil aggregates,

531 particularly when combined with plant removal. Instead, water addition actually increased the

532 formation of large macroaggregates if plants were present, perhaps due to increased activity of

533 roots and mycorrhizae. Therefore, plant-aggregate interactions depended on dry season length.

534 Surprisingly, the combination of two years of plant removal and water addition did not cause a

535 collapse in soil structure (although it did cause some surface crusting). If the soil binding agents

536 were readily soluble and decomposable by microbes, then water addition should have destroyed

537 macroaggregates. Instead, water favored macroaggregate formation, perhaps by increasing

538 fungal enmeshment or by allowing microbes to access C substrates to make EPS glues. However,

539 effects of irrigation on soil aggregate stability were small compared to plant removal.

540 The role of microbes in engineering dry soil became clearer in the laboratory. After

541 incubating soils for six months, the positive effect of microbes on macroaggregate formation was

542 indeed most prominent at intermediate levels of soil moisture. This pattern was not evident after

543 one week suggesting that aggregate formation by both microbes and abiotic processes requires

544 months to occur. It is also quite possible that soil microbial communities were negatively 
545 affected by the extreme disturbance of sieving and grinding, and one week was insufficient for

546 communities to recover. At $10 \%$ of soil water-holding capacity (WHC), macroaggregate

547 formation increased ten-fold in the presence of live microbes compared to sterile conditions. We

548 hypothesize that under the driest conditions (5\% WHC), which was approximately $-40 \mathrm{MPa}$ for

549 this soil (Priester et al., 2013), microbes could not access $C$ to be active (and hence to make EPS)

550 or to engage any other mechanism they may be using to produce aggregates. There was also

551 apparently insufficient water to form oxide "cements" and cation bridges (which are likely active

552 in the sterile, moist treatment). However, if provided a small amount of water (10\% WHC),

553 equivalent to adding $40 \mathrm{ml}$ of water per $\mathrm{kg}$ soil, perhaps $\mathrm{C}$ substrates were able to diffuse to

554 microbes with incentive to connect the dry soil matrix to access more resources, either via fungal

555 hyphal growth or bacterial EPS production (Roberson and Firestone, 1992; Ophir and Gutnick,

556 1994; Alvarez et al., 2004). The 10\% WHC treatment was equivalent to a soil water potential of -

$55710 \mathrm{MPa}$ which is wetter than the -14 MPa threshold required for diffusion (Manzoni et al., 2012).

558 Regardless of whether the pattern was driven by fungi or bacteria, our results indicate that

559 relatively little water was required to allow microbes to form macroaggregates.

560 The small amount of water required to initiate the formation of biogenic macroaggregates

561 has at least three far-reaching implications. First, this pattern suggests that as long as there is

562 enough moisture to encourage measurable microbial activity, microbes will act to create

563 aggregates. Second, small precipitation events in arid and seasonally-dry ecosystems may have

564 big effects on soil structure by activating microbes. Third, if we want to encourage native soil

565 microbes to produce beneficial effects in building soil structure in drought-prone agriculture and

566 other management contexts (e.g., restoration after wildfire, reduced windblown dust), then 
567 irrigation water can be conserved. A relatively small cost in water may have large benefits for 568 restoring soil structure.

Although abiotic processes did not appear to be important for macroaggregate formation

570 under the driest conditions, abiotic processes mattered in wetter soil. The positive effect of water

571 on aggregate formation was detectable after one week and after six months abiotic forces had

572 aggregated $>20 \%$ of the soil mass - in fact more soil was in macroaggregates in the sterile $20 \%$

573 WHC condition than was in aggregates in any of the live soil treatments. Perhaps water was

574 required to allow for mixing of oxide cements and arranging of cation bridges. In the case of

575 cation bridges, water likely plays a role in transporting cations to ideal locations to connect clay

576 surfaces with organic matter. If cations and organic matter must diffuse to build connections

577 among particles, then both water and time may be required to develop water-stable physicogenic 578 aggregates.

579 Surprisingly, under the wettest conditions simulated in the laboratory (20\% WHC), which 580 is typical during the wet season, microbes suppressed macroaggregate formation by $75 \%$

581 compared to sterilized soil and by $62 \%$ relative to the live soil at $15 \%$ WHC. One hypothesis for 582 this decrease might be that fungi are primarily responsible and that they prefer drier conditions 583 (Cornejo et al., 1994; Treseder et al., 2010; Yuste et al., 2011), in which case maybe 20\% WHC 584 would be too wet. This mechanism, however, would not explain the discrepancy between the live 585 and sterilized treatments. There is no obvious mechanism by which less fungi would interfere 586 with abiotic binding agents under wet conditions. The discrepancy indicates that biology was 587 somehow interfering with the chemical reactions that form physicogenic macroaggregates.

588 Alternative hypotheses would include: (1) microbes invested less C in EPS production under the 589 wettest conditions because soil was more hydrologically connected; and (2) microbes consumed 
590

591

592

593

594

595

596

597

598

599

600

601

602

603

604

605

606

607

608

609

610

611

612

organic matter or somehow otherwise prevented connections between organic matter and cations.

Fungi can translocate calcium and magnesium (Clarholm and Skyllberg, 2013), and both bacteria and fungi exude low-molecular-mass organic acids that may destabilize cation bridges by chelating the cations (Clarholm et al., 2015). Although the mechanism(s) still needs to be identified, our results reveal that microbes do not necessarily benefit soil aggregate stability.

We did not expect such small effects of field plant removal in the laboratory soil incubations. As opposed to the direct effects of root enmeshment and/or exudates in the field, the laboratory measurements were intended to isolate the indirect effects of plant litter via microbial priming. Neither abiotic nor biotic patterns of macroaggregate formation depended on the presence of fresh root residues. Therefore, as stated earlier, mechanisms of abiotic aggregate binding do not necessarily involve fresh plant litter. Furthermore, biotic patterns were also independent of plant removal suggesting that microbes did not depend on fresh plant $\mathrm{C}$ to make EPS; the most accessible $\mathrm{C}$ during drought was probably $\mathrm{C}$ associated with the mineral soil. This interpretation agrees with the hypothesis that labile $\mathrm{C}$ (i.e., plant $\mathrm{C}$ ) has a transient effect on aggregate stability whereas recalcitrant $\mathrm{C}$ (i.e., mineral-soil C) has less intense but longer-lasting effects (Abiven et al., 2009).

Our results also suggest that the shape of a macroaggregate may provide information about how it was formed (Oades, 1993; Pulleman et al., 2005; Velasquez et al., 2007). Physicogenic macroaggregates formed under sterilized, moist (20\% WHC) conditions appeared planar and angular at both macro- and micro-scales. In contrast, biogenic macroaggregates formed under live, dry (10\% WHC) conditions appeared spherical with rounded edges. Perhaps the planar structure of physicogenic aggregates reflects the underlying unidirectional binding of clay platelets, whereas the spherical structure of biogenic aggregates reflects the random, 
613 multidirectional binding of microbial glues and hyphae. Therefore, macroaggregate shape might

614 be helpful in monitoring the success of field efforts to improve soil aggregate stability using

615 native or introduced microbes. However, it remains unclear how the shape and origin of

616 macroaggregates relates quantitatively to soil $\mathrm{C}$ sequestration, nutrient retention, or erosion

617 control.

618 To conclude, on the drier side of the soil moisture spectrum, when there is not enough

619 water for the abiotic formation of water-stable macroaggregates, biology can engineer

620 macroaggregates. Dead plant roots can indeed help sustain large macroaggregates during the dry

621 season, whereas microbes sustain both small and large macroaggregates. Therefore, both dead

622 plants and live microbes have roles in maintaining structure in dry soils. There are clearly non-

623 additive interactions between the biotic and abiotic processes that form beneficial water-stable

624 macroaggregates in soil, but these interactions require water. In drier soil, microbiology

625 dominates.

626

627 Acknowledgements

628 We thank Kate McCurdy and Eric Massey at Sedgwick Reserve for their help with site 629 access and irrigation logistics. We thank Kenneth Marchus, Theo Tzeng, Peter Homyak, Kelsey

630 Dowdy, Kate Buckeridge, and Jinsong Zhao for their help in establishing and maintaining field

631 treatments. We thank Eric Slessarev for soil description, field help, and many discussions. We

632 thank Nicole Molinari and Carla D'Antonio for supplying rainout shelters. We thank David

633 Bustillo and Jonathon Chao for their help with aggregate separation. We thank Sage Davis and

634 the University of California Santa Barbara Micro-Environmental Imaging and Analysis Facility

635 for help in imaging aggregates. We thank Oliver Chadwick and Patricia Holden for their insight 
636 on interpreting data. This work was supported by National Science Foundation grant DEB-

$637 \quad 1145875$. 


\section{References}

Abiven, S., Menasseri, S., Chenu, C., 2009. The effects of organic inputs over time on soil aggregate stability—a literature analysis. Soil Biol. Biochem. 41, 1-12.

Alvarez, H.M., Silva, R.A., Cesari, A.C., Zamit, A.L., Peressutti, S.R., Reichelt, R., Keller, U., Malkus, U., Rasch, C., Maskow, T., Mayer, F., Steinbüchel, A., 2004. Physiological and morphological responses of the soil bacterium Rhodococcus opacus strain PD630 to water stress. FEMS Microbiol. Ecol. 50, 75-86.

Anderson, J.P.E., Domsch, K.H., 1978. A physiological method for the quantitative measurement of microbial biomass in soils. Soil Biol. Biochem. 10, 215-221.

Blankinship, J.C., Becerra, C.A., Schaeffer, S.M., Schimel, J.P., 2014. Separating cellular metabolism from exoenzyme activity in soil organic matter decomposition. Soil Biol. Biochem. 71, 68-75.

Bossuyt, H., Denef, K., Six, J., Frey, S.D., Merckx, R., Paustian, K., 2001. Influence of microbial populations and residue quality on aggregate stability. Appl. Soil Ecol. 16, 195208.

Briar, S.S., Fonte, S.J., Park, I., Six, J., Scow, K., Ferris, H., 2011. The distribution of nematodes and soil microbial communities across soil aggregate fractions and farm management systems. Soil Biol. Biochem. 43, 905-914.

Bronick, C.J., Lal, R., 2005. Soil structure and management: a review. Geoderma 124, 3-22.

Chantigny, M.H., Angers, D.A., Prévost, D., Vézina, L.-P., Chalifour, F.-P., 1997. Soil aggregation and fungal and bacterial biomass under annual and perennial cropping systems. Soil Sci. Soc. Am. J. 61, 262-267. 
660

661

662

663

664

665

666

667

668

669

670

671

672

673

674

675

676

677

678

679

680

681

682

Chenu, C., 1989. Influence of fungal polysaccharide, scleroglucan, on clay microstructures. Soil Biol. Biochem. 21, 299-305.

Chenu, C., Roberson, E.B., 1996. Diffusion of glucose in microbial extracellular polysaccharide as affected by water potential. Soil Biol. Biochem. 28, 877-884.

Cheshire, M.V., 1977. Origins and stability of soil polysaccharide. J. Soil Sci. 28, 1-10.

Clapp, C.E., Davis, R.J., Waugaman, S.H., 1962. The effect of rhizobial polysaccharides on aggregate stability. Soil Sci. Soc. Am. J. 26, 466-469.

Clarholm, M., Skyllberg, U., Rosling, A., 2015. Organic acid induced release of nutrients from metal-stabilized soil organic matter - the unbutton model. Soil Biol. Biochem. 84, 168176.

Clarholm, M., Skyllberg, U., 2013. Translocation of metals by trees and fungi regulates pH, soil organic matter turnover and nitrogen availability in acidic forest soils. Soil Biol. Biochem. 63, 142-153.

Cornejo, F.H., Varela, A., Wright, S.J., 1994. Tropical forest litter decomposition under seasonal drought: nutrient release, fungi and bacteria. Oikos 70, 183-190.

Cosentino, D., Chenu, C., Bissonnais, Y.L., 2006. Aggregate stability and microbial community dynamics under drying-wetting cycles in a silt loam soil. Soil Biol. Biochem. 38, 20532062.

Czarnes, S., Hallett, P.D., Bengough, A.G., Young, I.M., 2000. Root- and microbial-derived mucilages affect soil structure and water transport. Eur. J. Soil Sci. 51, 435-443.

Degens, B.P., Sparling, G.P., 1995. Repeated wet-dry cycles do not accelerate the mineralization of organic C involved in the macro-aggregation of a sandy loam soil. Plant Soil 175, 197203. 
Degens, B.P., 1997. Macro-aggregation of soils by biological bonding and binding mechanisms and the factors affecting these: a review. Aust. J. Soil Res. 35, 431-459.

De Gryze, S., Six, J., Brits, C., Merckx, R., 2005. A quantification of short-term macroaggregate dynamics: influences of wheat residue input and texture. Soil Biol. Biochem. 37, 55-66.

Denef, K., Six, J., Bossuyt, H., Frey, S.D., Elliott, E.T., Merckx, R., Paustian, K., 2001. Soil Biol. Biochem. 33, 1599-1611.

Elliott, E.T., 1986. Aggregate structure and carbon, nitrogen, and phosphorus in native and cultivated soils. Soil Sci. Soc. Am. J. 50, 627-633.

Fierer, N., Chadwick, O.A., Trumbore, S.E., 2005. Production of $\mathrm{CO}_{2}$ in soil profiles of a California annual grassland. Ecosystems 8, 412-429.

Flemming, H.-C., Wingender, J., 2010. The biofilm matrix. Nature Reviews 8, 623-633.

Fogel, R., 1983. Root turnover and productivity of coniferous forests. Plant Soil 71, 75-85.

Foster, R.C., 1981. Polysaccharides in soil fabrics. Science 214, 665-667.

Ghani, A., Dexter, M., Perrott, K.W., 2003. Hot-water extractable carbon in soils: a sensitive measurement for determining impacts of fertilisation, grazing and cultivation. Soil Biol. Biochem. 35, 1231-1243.

Gupta, V.V.S.R., Germida, J.J., 1988. Distribution of microbial biomass and its activity in different soil aggregate sizes classes as affected by cultivation. Soil Biol. Biochem. 20, 777-787.

Haynes, R.J., Francis, G.S., 1993. Changes in microbial biomass C, soil carbohydrate composition and aggregate stability induced by growth of selected crop and forage species under field conditions. J. Soil Sci. 44, 665-675. 
Haynes, R.J., Beare, M.H., 1997. Influence of six crop species on aggregate stability and some labile organic matter fractions. Soil Biol. Biochem. 29, 1647-1653.

Holden, P.A., 2011. How do the microhabitats framed by soil structure impact soil bacteria and the processes they catalyze?, in: Ritz, K., Young, I. (Eds.), The Architecture and Biology of Soils: Life in Inner Space. CAB International, Oxfordshire, pp. 1-62.

Hu, S., Coleman, D.C., Beare, M.H., Hendrix, P.F., 1995. Soil carbohydrates in aggrading and degrading agroecosystems: influences of fungi and aggregates. Agr. Ecosyst. Environ. $54,77-88$.

Jastrow, J.D., 1996. Soil aggregate formation and the accrual of particulate and mineralassociated organic matter. Soil Biol. Biochem. 28, 665-676.

Jastrow, J.D., Miller, R.M., Boutton, T.W., 1996. Carbon dynamics of aggregate-associated organic matter estimated by carbon-13 natural abundance. Soil Sci. Soc. Am. J. 60, 801807.

Keil, R.G., Mayer, L.M., 2014. Mineral matrices and organic matter. Treatise Geochem. Org. Geochem. 12, 337-359.

Keim, R., Kandeler, E., 1997. Stabilization of aggregates by the microbial biomass as affected by soil texture and type. Appl. Soil Ecol. 5, 221-230.

Kong, A.Y.Y., Scow, K.M., Córdova-Kreylos, A.L., Holmes, W.E., Six, J., 2011. Microbial community composition and carbon cycling within soil microenvironments of conventional, low-input, and organic cropping systems. Soil Biol. Biochem. 43, 20-30.

Lavelle, P., Bignell, D., Lepage, M., Wolters, V., Roger, P., Ineson, P., Heal, O.W., Dhillion, S., 1997. Soil function in a changing world: the role of invertebrate ecosystem engineers. Eur. J. Soil Biol. 33, 159-193. 
Lützow, M.V., Kögel-Knaber, I., Ekschmitt, K., Matzner, E., Guggenberger, G., Marschner, B., Flessa, H., 2006. Stabilization of organic matter in temerate soils: mechanisms and their relevance under different soil conditions - a review. Eur. J. Soil Sci. 57, 426-445.

Manzoni, S., Schimel, J.P., Porporato, A., 2012. Responses of soil microbial communities to water stress: results from meta-analysis. Ecology 93, 930-938.

Molope, M.B., Grieve, I.C., Page, E.R., 1987. Contributions of fungi and bacteria to aggregate stability of cultivates soils. J. Soil Sci. 38, 71-77.

Muneer, M., Oades, J.M., 1989. The role of Ca-organic interactions in soil aggregate stability. I. laboratory studies with ${ }^{14} \mathrm{C}$-glucose, $\mathrm{CaCO}_{3}$ and $\mathrm{CaSO}_{4} \cdot 2 \mathrm{H}_{2} \mathrm{O}$. Aust. J. Soil Res. 27, 389399.

Oades, J.M., 1988. The retention of organic matter in soils. Biogeochem 5, 35-70.

Oades, J.M., Waters, A.G., 1991. Aggregate hierarchy in soils. Aust. J. Soil Res. 29, 815-828.

Oades, J.M., 1993. The role of biology in the formation, stabilization and degradation of soil structure. Geoderma 56, 377-400.

Ophir, T., Gutnick, D.L., 1994. A role of exopolysaccharides in the protection of microorganisms from desiccation. Appl. Environ. Microb. 60, 740-745.

Peng, X., Horn, R., Hallett, P., 2015. Soil structure and its functions in ecosystems: phase matter and scale matter. Soil Till. Res. 146, 1-3.

Priester, J.H., Ge, Y., Chang, V., Stoimenov, P.K., Schimel, J.P., Stucky, G.D., Holden, P.A., 2013. Assessing interactions of hydrophilic nanoscale $\mathrm{TiO}_{2}$ with soil water. J. Nanopart. Res. 15, 1899, doi:10.1007/s11051-013-1899-4. 
Pulleman, M.M., Six, J., Uyl, A., Marinissen, J.C.Y., Jongmans, A.G., 2005. Earthworms and management affect organic matter incorporation and microaggregate formation in agricultural soils. Appl. Soil. Ecol. 29, 1-15.

Redmile-Gordon, M.A., Brookes, P.C., Evershed, R.P., Goulding, K.W.T., Hirsch, P.R., 2014. Measuring the soil-microbial interface: extraction of extracellular polymeric substances (EPS) from soil biofilms. Soil Biol. Biochem. 72, 163-171.

Roberson, E.B., Firestone, M.K., Sarig, S., 1991. Cover crop management of polysaccharidemediated aggregation in an orchard soil. Soil Sci. Soc. Am. J. 55, 734-739.

Roberson, E.B., Firestone, M.K., 1992. Relationship between desiccation and exopolysaccharide production in a soil Pseudomonas sp. Appl. Environ. Microb. 58, 1284-1291.

Schimel, J.P., Schaeffer, 2012. Microbial control over carbon cycling in soil. Front. Microbiol. 3, 348, doi:10.3389/fmicb.2012.00348.

Six, J., Elliott, E.T., Paustian, K., 2000. Soil macroaggregate turnover and microaggregate formation: a mechanism for $\mathrm{C}$ sequestration under no-tillage agriculture. Soil Biol. Biochem. 32, 2099-2103.

Six, J., Bossuyt, H., Degryze, S., Denef, K., 2004. A history of research on the link between (micro)aggregates, soil biota, and soil organic matter dynamics. Soil Till. Res. 79, 7-31.

Six, J., Paustian, K., 2014. Citation Classic XII: Aggregate-associated soil organic matter as an ecosystem property and measurement tool. Soil Biol. Biochem. 68, A4-A9.

Tisdall, J.M., Oades, J.M., 1982. Organic matter and water-stable aggregates in soils. J. Soil Sci. $33,141-163$.

Tisdall, J.M., 1994. Possible role of soil microorganisms in aggregation in soils. Plant Soil 159, $115-121$. 
772 Treseder, K.K., Schimel, J.P., Garcia, M.O., Whiteside, M.D., 2010. Slow turnover and 773 production of fungal hyphae during a California dry season. Soil Biol. Biochem. 42, $774 \quad 1657-1660$.

775 Velasquez, E., Pelosi, C., Brunet, D., Grimaldi, M., Martins, M., Rendeiro, A.C., Barrios, E., 776 Lavelle, P., 2007. This ped is my ped: visual separation and near infrared spectra allow 777 determination of the origins of soil macroaggregates. Pedobiologia 51, 75-87.

778 West, A.W., Sparling, G.P., 1986. Modifications to the substrate-induced respiration method to 779 permit measurement of microbial biomass in soils of differing water contents. J.

$780 \quad$ Microbiol. Meth. 5, 177-189.

781 Yuste, J.C., Peñuelas, J., Estiarte, M., Garcia-Mas, J., Mattana, S., Ogaya, R., Pujol, M., Sardans, 782 J., 2011. Drought-resistant fungi control soil organic matter decomposition and its 783 response to temperature. Glob. Change Biol. 17, 1475-1486. 


\section{Figure Legends}

785 Fig. 1. Soil volumetric water content $(0-10 \mathrm{~cm}$ deep $)$ in field plots with varying levels of plant removal and irrigation. Symbols show mean and standard error bars. The long dry season plots

787 experienced ambient precipitation. In order to prevent soils from drying below 10\% volumetric 788 water content, the no dry season plots were irrigated approximately biweekly between 14 May and 6 November in 2013 and between 23 May and 21 October in 2014.

Fig. 2. Linear regressions showing the influence of grassland plant removal on the average size of water-stable soil aggregates. 'Long dry season, Year 1' soils (dashed line) were collected in January 2014 after 9 months without precipitation and 1 y of plant removal treatments established near Santa Ynez, California. 'Long dry season, Year 2' soils (gray line) were collected from the same plots in September 2014 after six months without precipitation and 2 y of plant removal. 'No dry season, Year 2' soils (black line) were collected in September 2014

797 from different plots exposed to 2 years of plant removal and biweekly irrigation to prevent soil 798 desiccation. Points show the mean and standard error for each combination of plant removal, 799 water availability, and year $(\mathrm{N}=3)$.

Fig. 3. Effect of 2 years of grassland plant removal (0\% vs. $90 \%$ removal) on the size 802 distribution of water-stable soil aggregates. 'Long dry season' soils were exposed to ambient conditions with typical summer dryness. 'No dry season' soils were irrigated biweekly during the

804 summer to prevent drying. Large macroaggregates ('large macro') were $2000 \_9000 \mu \mathrm{m}$ in 805 diameter. Small macroaggregates ('small macro') were 250—2000 $\mu \mathrm{m}$. Microaggregates 806 ('micro') were $53-250 \mu \mathrm{m}$. Clay and silt were less than $53 \mu \mathrm{m}$. Columns and bars show means 
807 and standard errors $(\mathrm{N}=3)$. Asterisks $(*)$ indicate statistically significant effect of plant removal 808 in a pooled $t$-test at an alpha level of 0.05 .

810 Fig. 4. Environmental scanning electon microscope (ESEM) images of "field-fresh" water-stable 811 macroaggregates in grassland soils with plants (top) and in plots where plants were removed by

812 hand for 2 years (bottom). Scale bars at the bottom of each image show $100 \mu \mathrm{m}$.

Fig. 5. Soil microbial biomass estimated by glucose-induced respiration after six months of laboratory exposure to all combinations of three treatments: (i) moisture $(5 \%, 10 \%, 15 \%$, and

$81620 \%$ of soil water-holding capacity (WHC)); (2) fresh carbon input (with and without plants);

817 and (3) sterilization (with and without chloroform). 'Sterilized' soils were continuously

818 fumigated with chloroform vapor and 'live' soils had no chloroform. Columns and bars show

819 means and standard errors $(\mathrm{N}=3)$. Letters indicate effects of altered soil moisture for each

820 treatment combination using Tukey HSD post hoc tests at an alpha level of 0.05 . An asterisk (*)

821 indicates significant difference between live and sterile treatments in $t$-test at an alpha level of

8220.05 for each combination of moisture and plant $\mathrm{C}$ input. Dashed line shows the initial level of

823 glucose-induced respiration for all treatments at the beginning of the 6-month incubations.

825 Fig. 6. Effect of soil moisture on the formation of water-stable macroaggregates (> $250 \mu \mathrm{m})$ as a 826 function of microbial biomass and plant carbon input in a six-month incubation experiment. All 827 treatments began with no macroaggregates and were maintained in the laboratory at 5\%, 10\%, $82815 \%$, and $20 \%$ of soil water-holding capacity (WHC). 'Sterilized' soils were continuously 829 fumigated with chloroform vapor and 'live' soils had no chloroform. Soils 'without plants' were 
830 collected from field plots where plants were removed for $1 \mathrm{y}$, and soils 'with plants' were from

831 unmanipulated plots. Columns and bars show means and standard errors $(\mathrm{N}=3)$. Letters indicate

832 effects of altered soil moisture for each treatment combination using Tukey HSD post hoc tests

833 at an alpha level of 0.05 . An asterisk (*) indicates significant difference between live and sterile

834 treatments in $t$-test at an alpha level of 0.05 for each combination of moisture and plant $\mathrm{C}$ input.

836 Fig. 7. Effect of soil moisture on the abiotic and biotic formation of water-stable

837 macroaggregates after a one-week incubation experiment. All laboratory treatments began with

838 recent plant carbon inputs and no macroaggregates. Soils were maintained at 5\%, 10\%, 15\%, and

$83920 \%$ of water-holding capacity (WHC). 'Sterilized' soils were continuously fumigated with

840 chloroform vapor whereas 'live' soils had no chloroform. Columns and bars show means and

841 standard errors $(\mathrm{N}=3)$. Letters indicate effects of soil moisture (or lack thereof) for each

842 sterilization treatment using Tukey HSD post hoc tests at an alpha level of 0.05 . An asterisk (*)

843 indicates significant difference between live and sterile treatments in $t$-test at an alpha level of

$844 \quad 0.05$ for each combination of moisture and plant $\mathrm{C}$ input.

845

846 Fig. 8. Images of water-stable macroaggregates formed during 6-month soil incubations under

847 sterile moist conditions (left side) and live dry conditions (right side). Overhead macroscopic

848 views show the jagged, angular shape of the abiotically formed aggregates $(a)$ and the round

849 shape of the biotically formed aggregates ( $b$; scale shows $1 \mathrm{~cm}$ with $\mathrm{mm}$ increments). Side

850 macroscopic views show the planar shape of physicogenic aggregates $(c)$ and the three-

851 dimensional, spherical shape of biogenic aggregates $(d)$. Environmental scanning electron 
852 microscope (ESEM) images show the microstructure of physicogenic ( $e$; scale bar shows $20 \mu \mathrm{m})$

853 and biogenic aggregates ( $f$; scale bar shows $50 \mu \mathrm{m})$. 
Table 1. Effect of 1 year of plant removal on belowground properties $(0-10 \mathrm{~cm}$ deep $)$ in a seasonally dry grassland near Santa Ynez, California. All variables were measured near the end of the 2013 dry season to characterize initial conditions for the laboratory soil incubations.

Parentheses show standard errors $(\mathrm{N}=3)$. Asterisks $(*)$ indicate significant difference between $0 \%$ plant removal ('with plants') and $90 \%$ plant removal ('without plants') in a pooled $t$-test at an alpha level of 0.05 .

\begin{tabular}{llcrc} 
Response variable & Units & With plants & Without plants & p-value \\
\hline Root biomass & $\mathrm{mg} \mathrm{roots} \mathrm{g}^{-1}$ soil & $6.0(1.4)$ & $0.8(0.3)$ & $0.024^{*}$ \\
Wet-up respiration & $\mu \mathrm{g} \mathrm{CO}_{2}-\mathrm{C} \mathrm{g}^{-1}$ soil h$^{-1}$ & $5.7(0.1)$ & $3.7(0.4)$ & $0.0064^{*}$ \\
Glucose-induced respiration & $\mu \mathrm{g} \mathrm{CO}_{2}-\mathrm{C} \mathrm{g}^{-1} \mathrm{soil} \mathrm{h}^{-1}$ & $6.6(0.1)$ & $6.9(0.2)$ & 0.32 \\
Water-extractable organic C & $\mu \mathrm{g} \mathrm{C} \mathrm{g}^{-1}$ soil & $151.4(12.4)$ & $206.5(23.4)$ & 0.11 \\
Water-extractable N & $\mu \mathrm{g} \mathrm{N} \mathrm{g}^{-1}$ soil & $11.7(1.1)$ & $48.8(10.3)$ & $0.023^{*}$ \\
Total C & $\mathrm{mg} \mathrm{C} \mathrm{g}^{-1}$ soil & $21.6(1.2)$ & $24.9(1.5)$ & 0.12 \\
Total N & $\mathrm{mg} \mathrm{N} \mathrm{g}^{-1}$ soil & $1.9(0.1)$ & $2.3(0.2)$ & 0.12
\end{tabular}





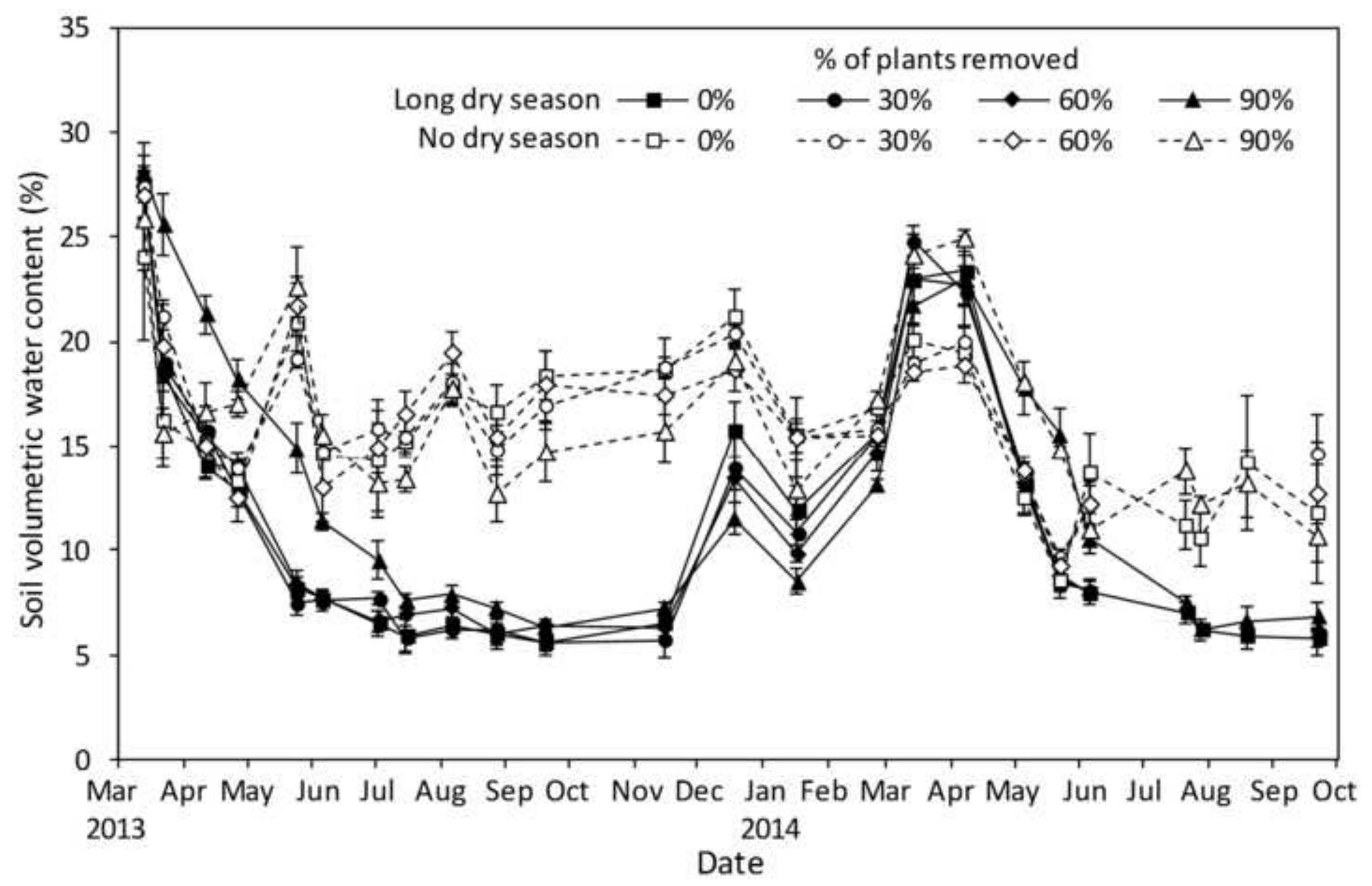




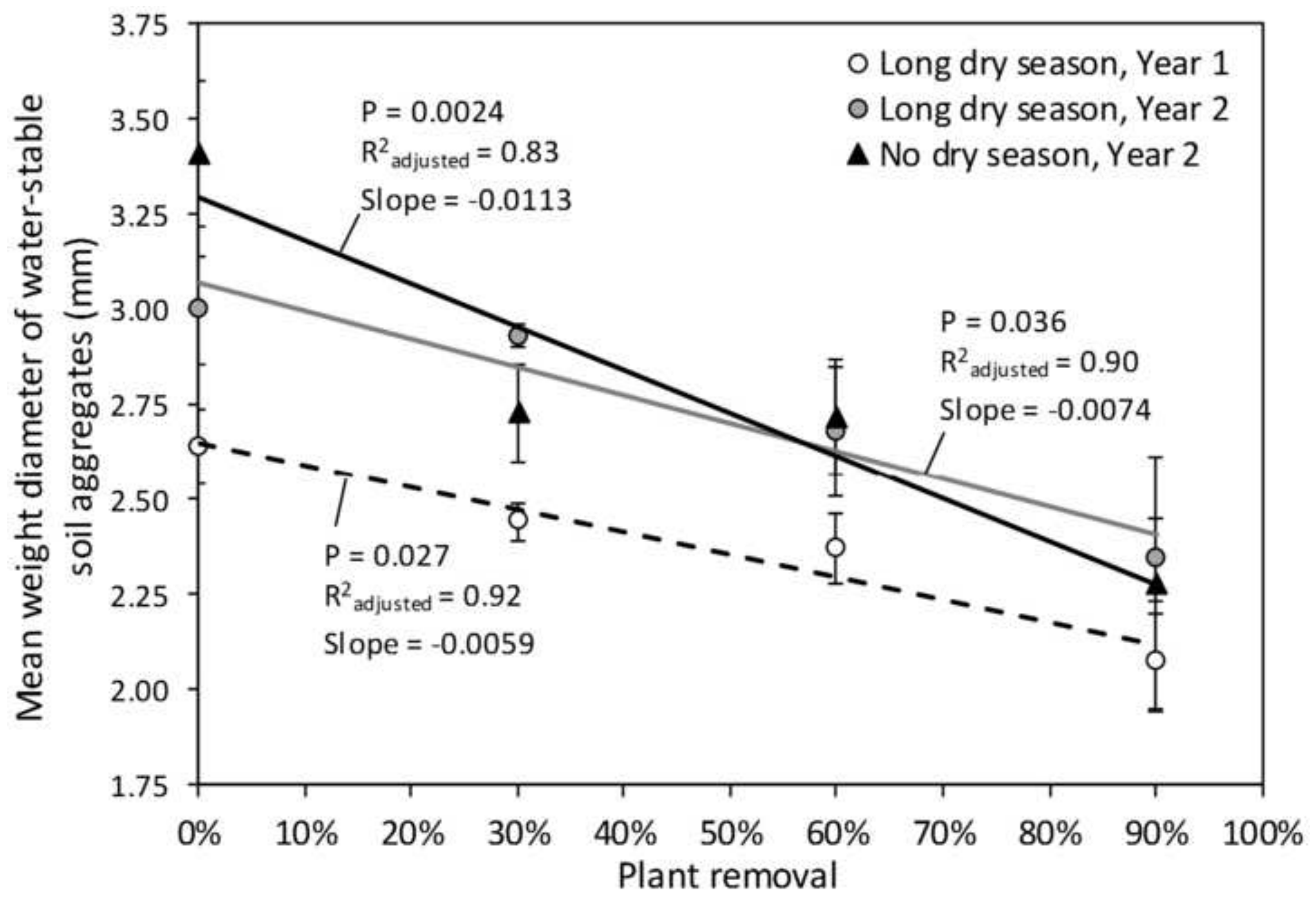




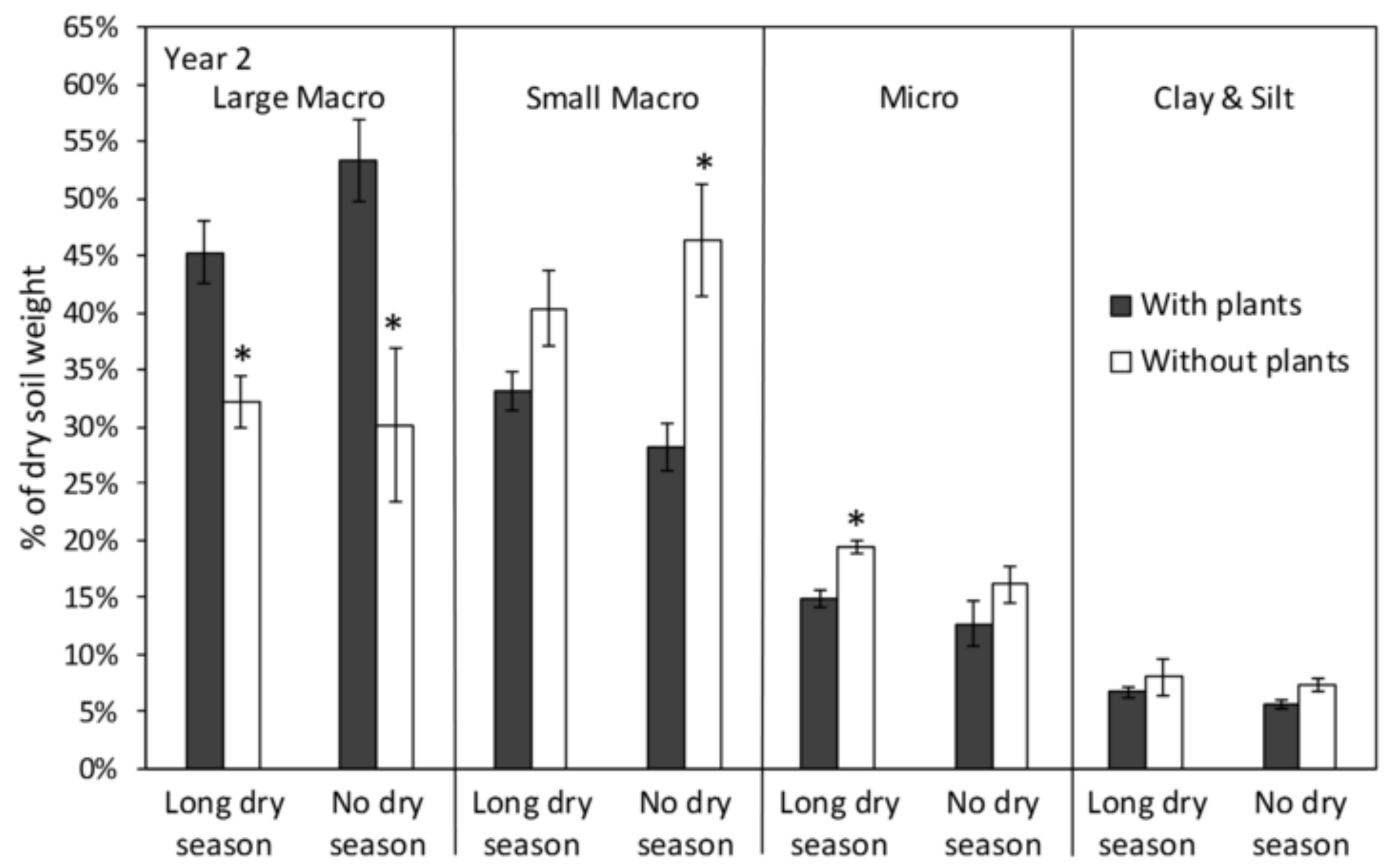


Aggregates from plots with plants
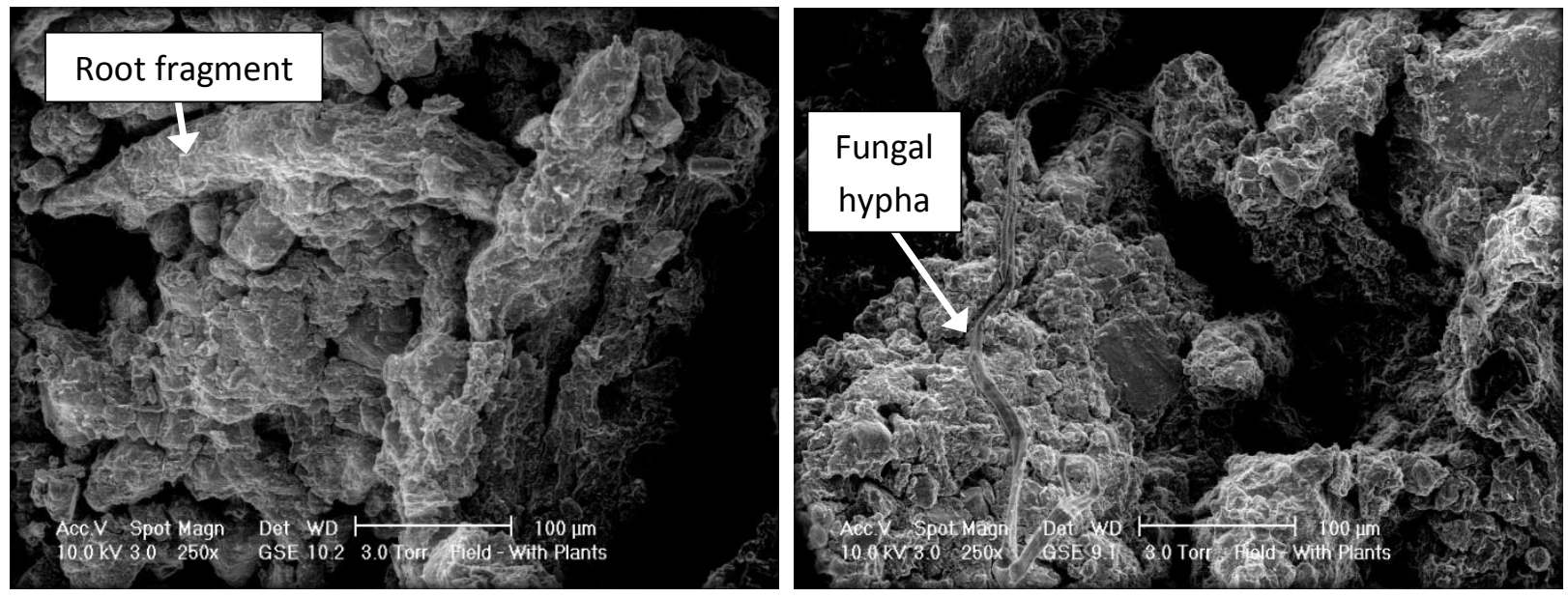

Aggregates from plots without plants
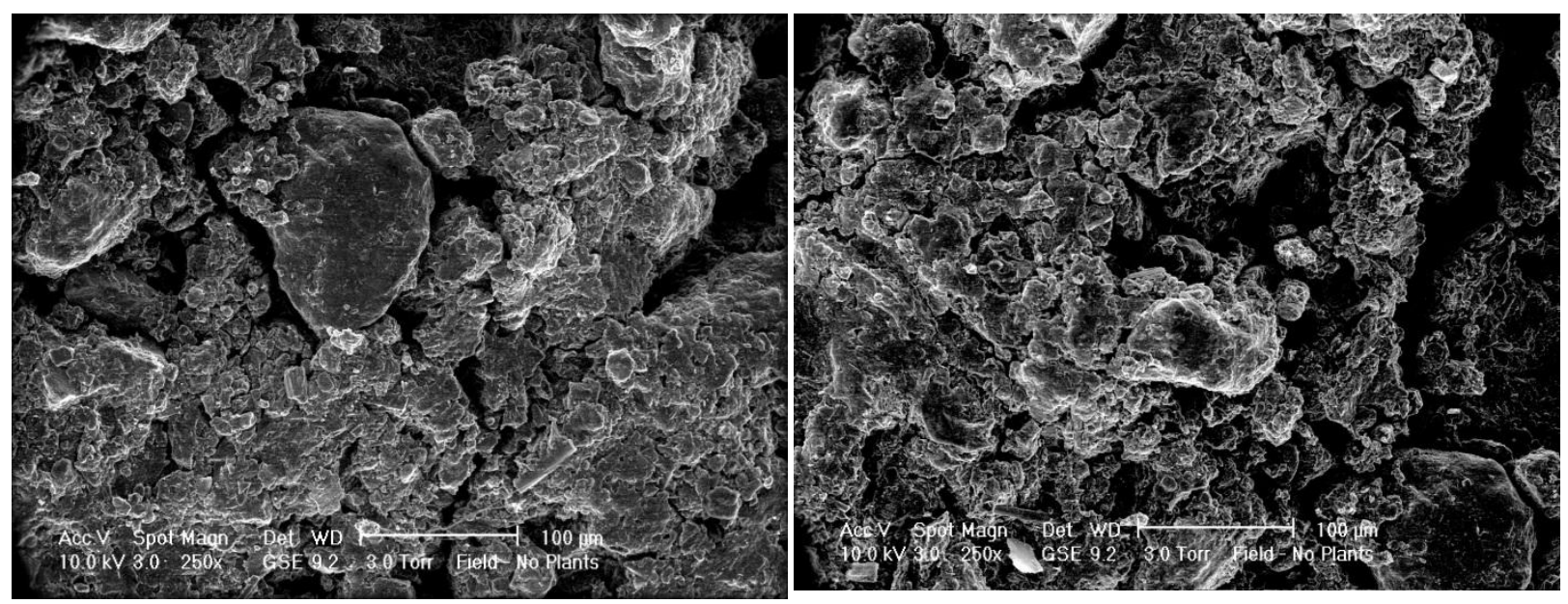


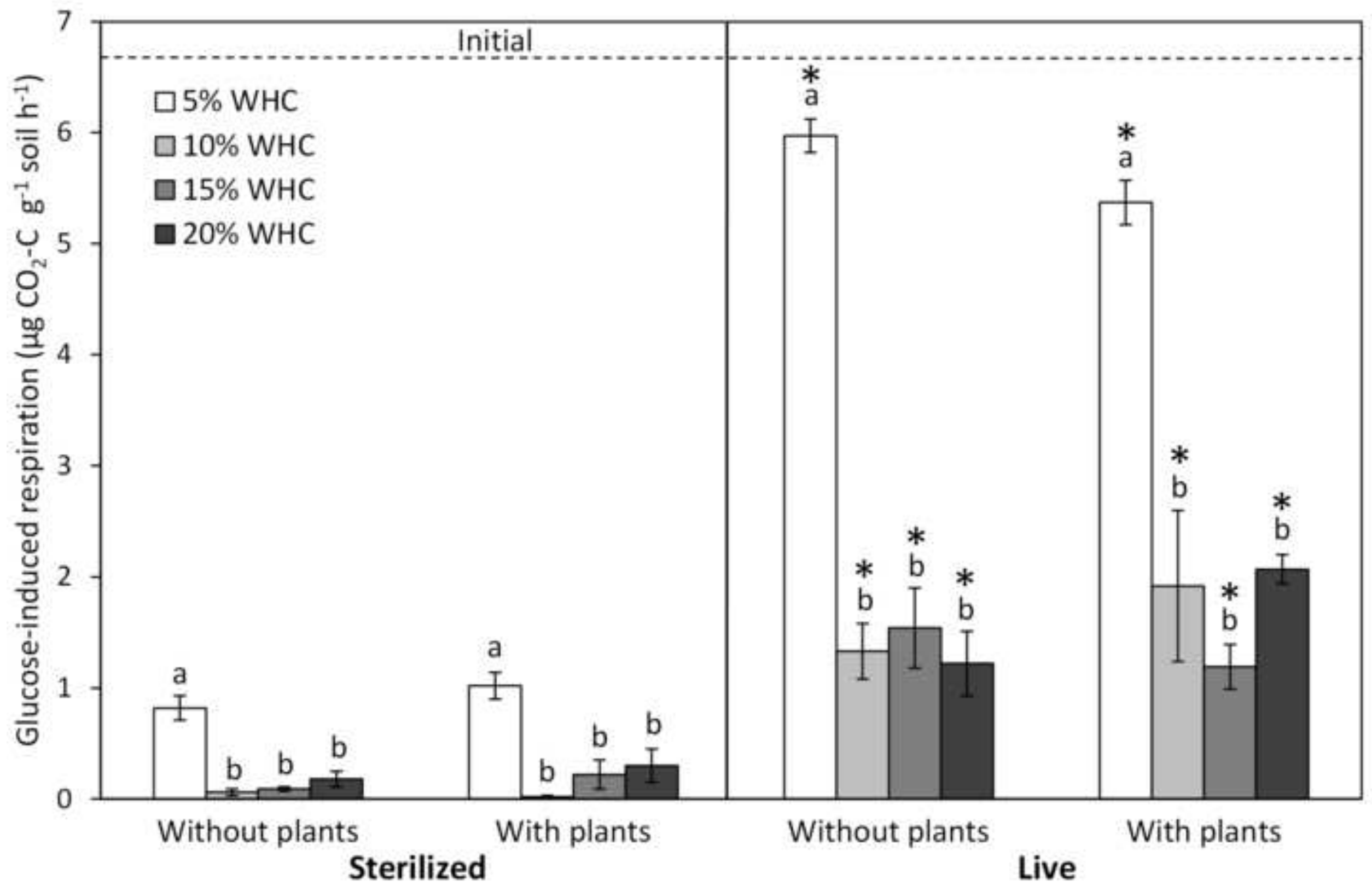




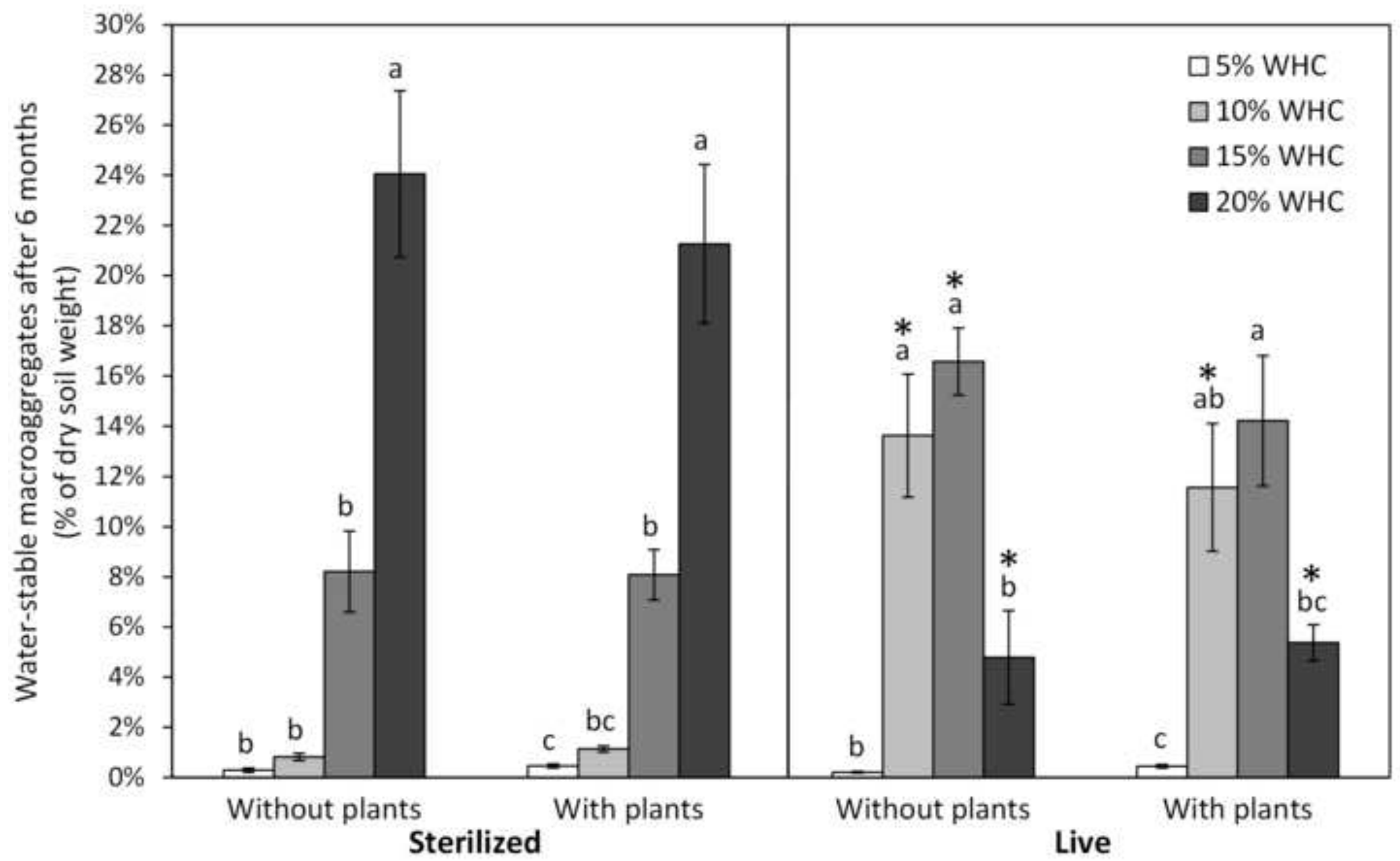




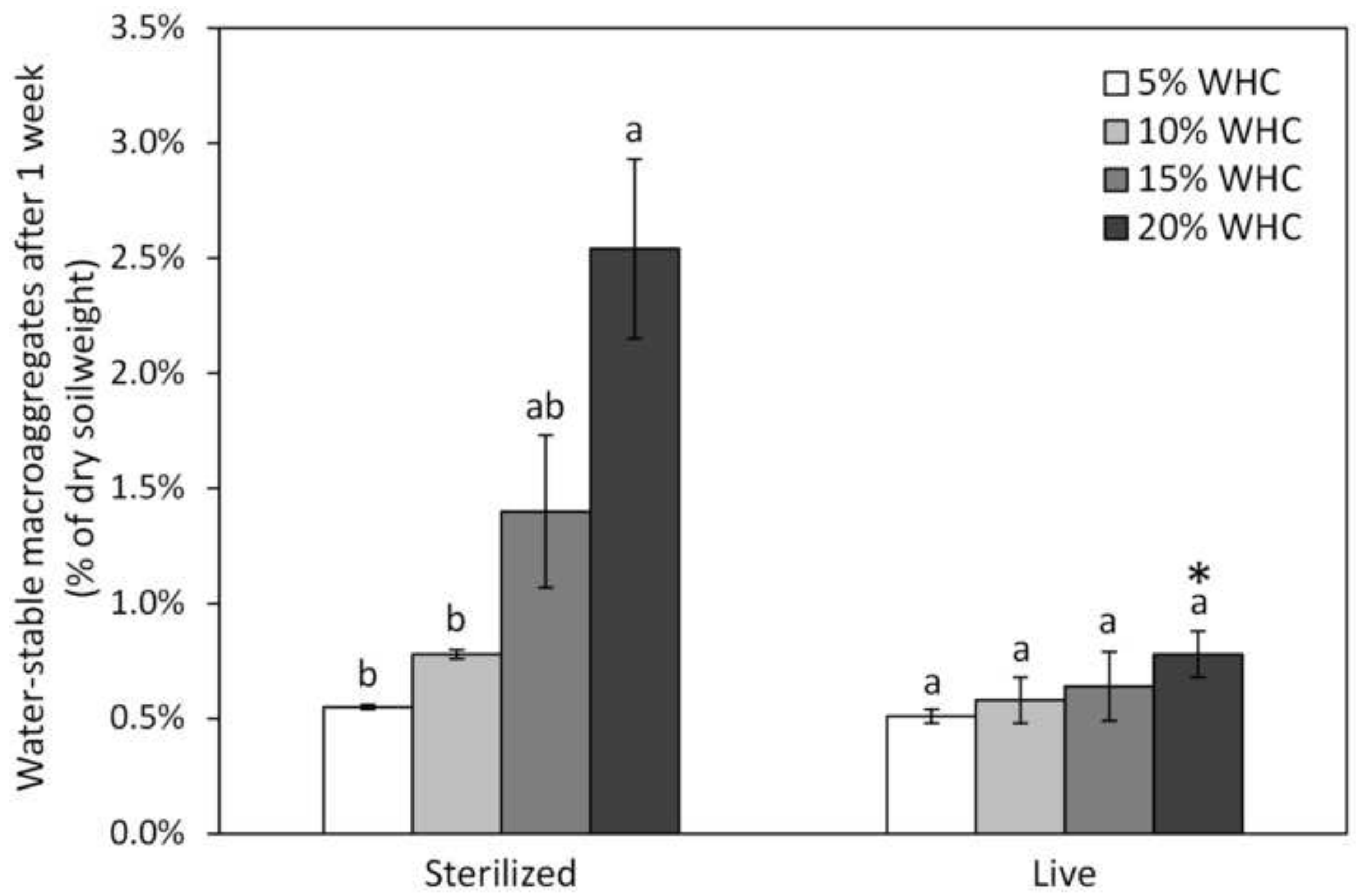


Physicogenic aggregate

(sterile, 20\% WHC)

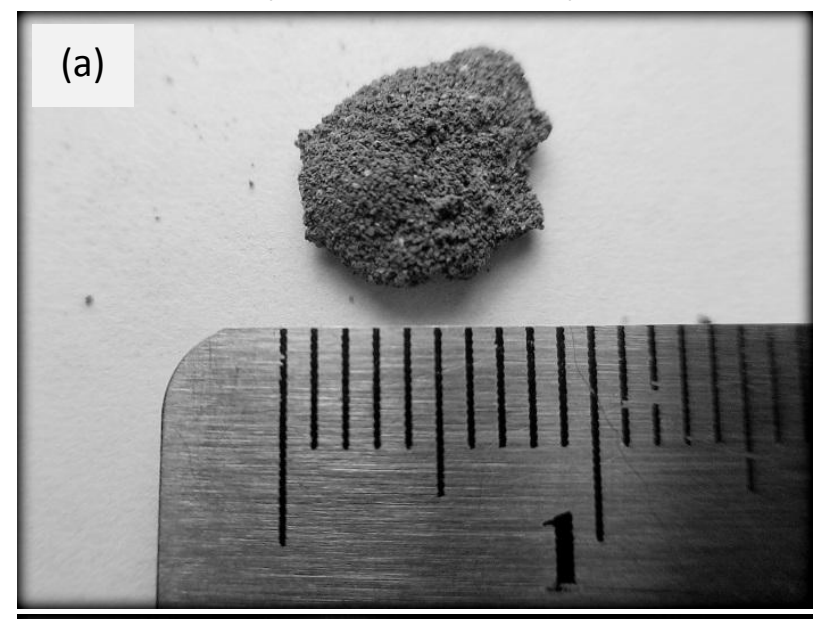

(c)

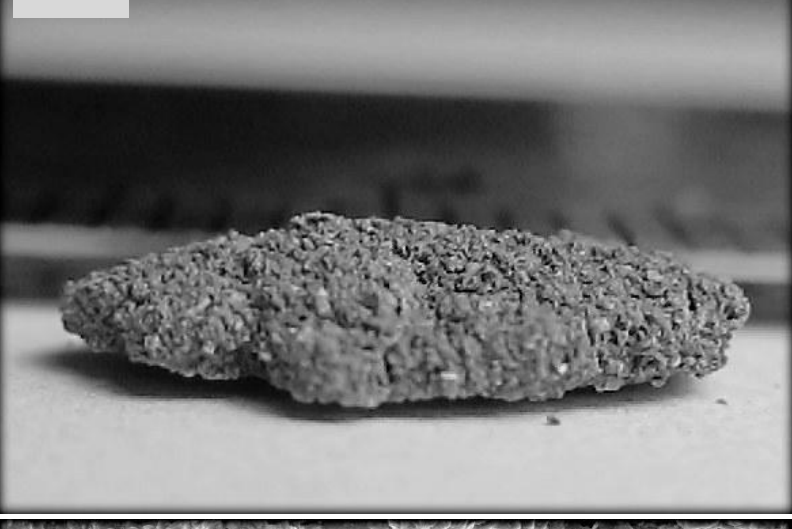

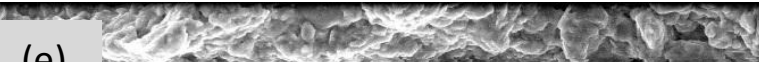

(e)

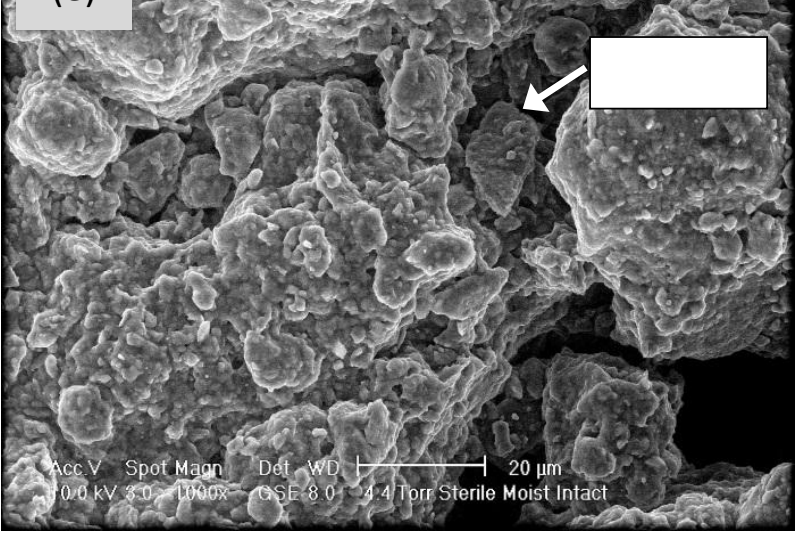

Biogenic aggregate

(live, 10\% WHC)

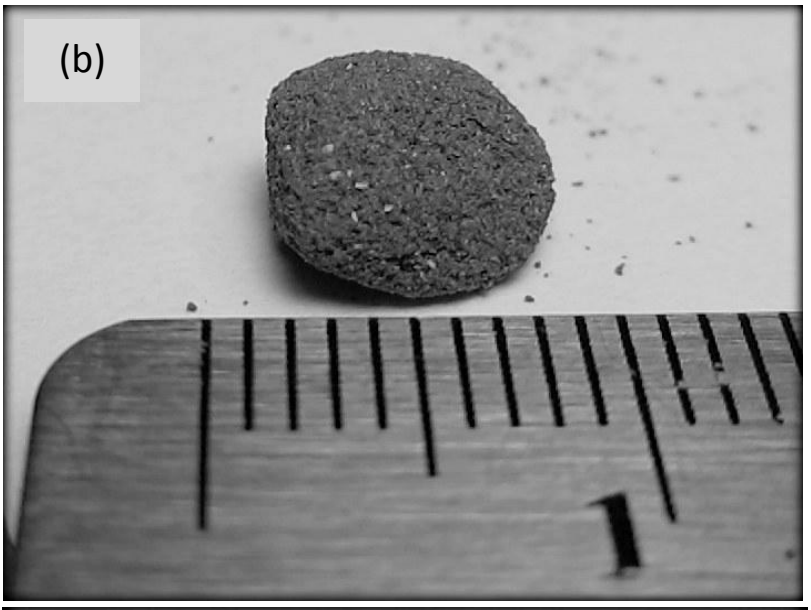

(d)
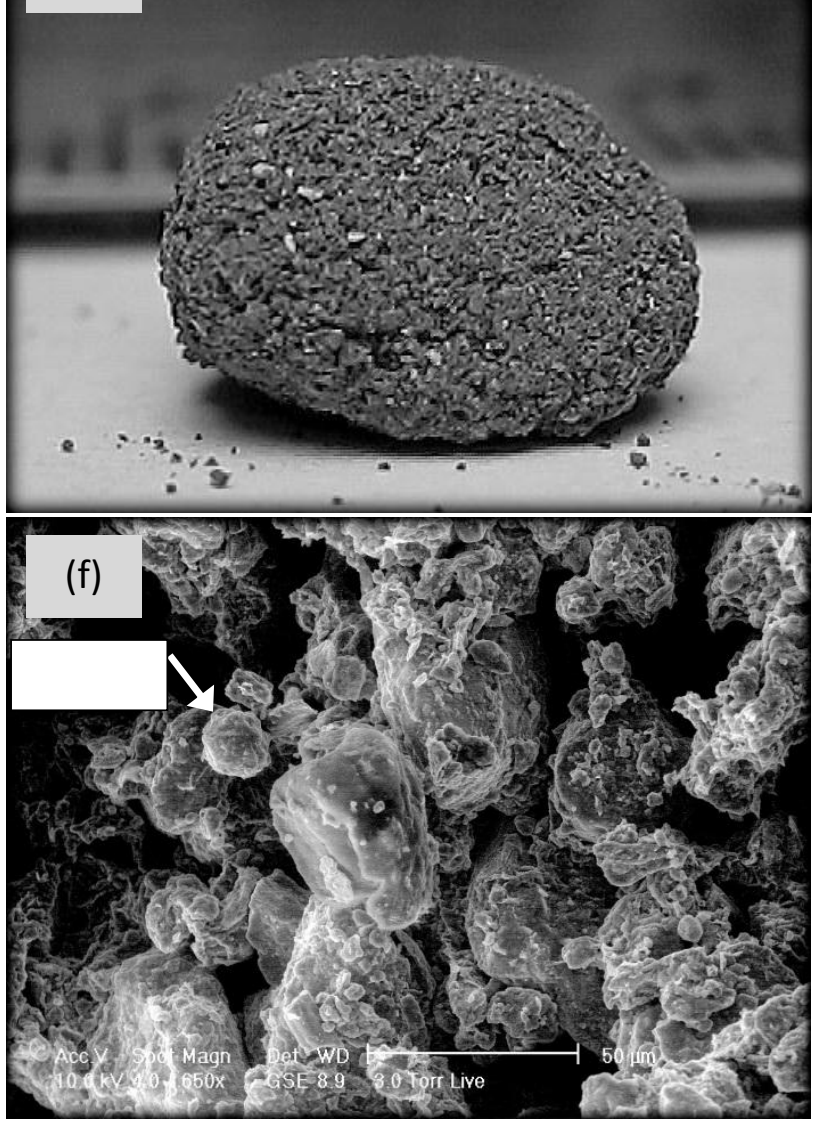